\title{
COMPARATIVE STUDY BETWEEN POLAND AND SOUTH AFRICA WIND CLIMATES, THE RELATED DAMAGE AND IMPLICATIONS OF ADOPTING THE EUROCODE FOR WIND ACTION ON BUILDINGS
}

\author{
A. GOLIGER ${ }^{1}$, J. ŻURANSKI ${ }^{2}$, M. GIŻEJOWSKI ${ }^{3}$, M. GACZEK $^{4}$, J. RETIEF ${ }^{5}$, \\ A. KRUGER ${ }^{6}$, P. DUNAISKI ${ }^{\dagger}$, S. FISZER ${ }^{7}$, M. ĆWIK ${ }^{8}$
}

Wind constitutes one of the major environmental factors affecting the design and performance of built environment. Each country has its unique climatic wind conditions, and the way in which these are considered and implemented in the structural design, is important. An implementation or adoption of any new engineering design stipulations introduces a formidable challenge to the developers of the standards and the design profession. This has been experienced in some of the countries (e.g. the UK, Australia and the USA), where processes of modernising the outdated codification took place in the past. Although both Poland and South Africa are currently at the early implementation stage of the new wind loading design stipulations, there is a major difference between the circumstances of the two countries. Poland, as an EU member state, has a compulsory obligation to adopt the new uniform standarisation requirements, within a stipulated time-frame. The South African code developers, after a thorough investigation process which will be highlighted in the paper, decided voluntarily to adopt the Eurocode as the primary model document.

Key words: wind climate, wind damage, wind loading, structural design standards.

\section{THE IMPACT OF STRONG WIND EVENTS ON STRUCTURAL PERFORMANCE OF THE BUILT ENVIRONMENT}

Throughout the world, wind forms one of the dominating environmental loadings affecting structural design and performance, and is also responsible for a large percent-

$1 \mathrm{PhD}$, Council for Scientific and Industrial Research (CSIR), Pretoria, South Africa; email: agoliger@csir.co.za

$2 \mathrm{PhD}$, DSc, Professor at the Building Research Institute, Warsaw, Poland; email: jzuranski@pro.onet.pl

3 Prof, PhD, DSc, Professor at the Warsaw University of Technology, Warsaw, Poland; email: m.gizejowski@il.pw.edu.pl

4 PhD, Poznan University of Technology, Poznan, Poland; email: mariusz.gaczek@put.poznan.pl

5 PhD, Professor at Stellenbosch University, South Africa; email: jvr@maties.sun.ac.za

6 PhD, South African Weather Service, Pretoria, South Africa; email: andries.kruger@weathersa.co.za

7 MSc, Poznan University of Technology, Poznan, Poland; email: slawomir.fiszer@put.poznan.pl

$\dagger$ deceased, formerly Professor at Stellenbosch University, South Africa

${ }^{8}$ MSc, PhD Student, Warsaw University of Technology, Poland; email: michal.cwik@op.pl 
age of disastrous events in the built-up environment. In the absence of snow and ice loadings, this is more evident on the African continent. This issue becomes even more relevant in view of the constant pursuit for more economic designs of structures and the development of materials with higher strength, which in many cases lead to the development and use of lighter components and also the introduction of "leaner" design techniques.

In view of these technological trends, combined with the global concerns relating to possible climatic change, a significant amount of theoretical and experimental research has been carried out throughout the world on the effects of wind on structures and the development of adequate standards to safeguard against excessive damage.

Despite these efforts, insurance statistics suggest that losses due to windstorm disasters continue to rise (Berz [4], Munich Re [39]). This could partly be attributed to an increase in the population and the related extent of the built environment; it also raises questions as to the possibility of global environmental change leading to an increase in the occurrence of severe windstorms (Kasperski [31], Stansfield [48]). The situation suggests that the scientifically derived knowledge on wind-resistant structural design has not yet been implemented across the entire construction sector.

$\%$ of catastrophic events

(total number 1750)

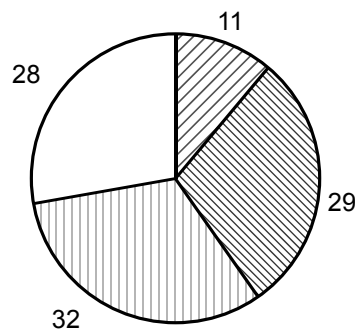

$\%$ of death $1994-1996$

(total number 40825)

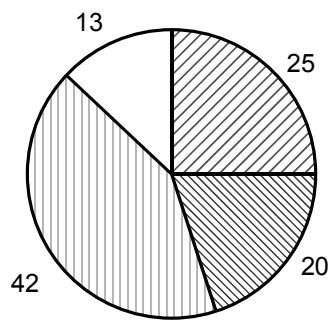

$\%$ of economic loss (total amount USD 310 bn)

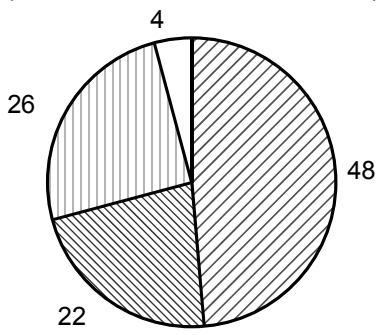

Fig. 1. Comparison of natural disasters. 


\section{WiND CLIMATE CONSIDERATIONS}

All natural disasters can have enormous socio-economic impact. Windstorms are regarded as one of the major types of disasters and their impact is demonstrated in Figure 1, in which an analysis of the world's catastrophes for the period 1994-1996 is given (derived from Munich Re [40]). The statistics on the number of events and their consequences are compared. It can be seen that windstorms constitute nearly $30 \%$ of catastrophes, cause $20 \%$ of deaths and $22 \%$ of economic loss. According to Davenport [14] losses due to wind exceeded those due to earthquakes, on an annual global basis.

Wind climate constitutes the critical input factor which determines the wind loadings and related damage to structures in a specific geographic area. The climatic wind conditions (i.e. the characteristics and geographical extent of severe winds) have to be accounted for in any structural design process. For small countries of the world (e.g. some of the European or central American countries) the wind climatic conditions are typically uniform, from a geographical point of view. This is not applicable to larger countries, which include different climatic regimes that directly affect the characteristics of strong wind events; these should be reflected in the stipulations of the relevant wind loading design codification.

The issue of variability of wind climatic influences can be demonstrated by a comparison of selected types of wind and storm-related events affecting Poland and South Africa as presented in Figure 2 (derived from Munich Re [40]).

In Figure 2, the percentages of areas of both countries affected by specific types of events, and in terms of the related risks, are compared. Of particular interest is the fair uniformity of the wind climatic exposure of Poland, e.g. most of Poland is at average risk due to winter storms while the South African exposure varies from none to high. A similar is observed for tornado risks. In this context, it is surprising to note the similarities in the distribution of risks of lightning, which typically correlates with thunderstorm activity. This issue will be demonstrated further in the following subsections in which the wind climatic characteristics of Poland and South Africa are compared.

\subsection{Poland}

Poland is located in the centre of continental Europe, with its northern borders facing the Baltic Sea. Due to this position two types of climatic conditions prevail, namely the continental and coastal; this situation is also reflected in the types of strong wind events affecting the country. The general climate is also influenced by the orographic situation in which most of the country is fairly flat, situated below $300 \mathrm{~m}$ above sea level, while the southern borders are dominated by the two prominent mountain ranges of Carpathians and Sudetes.

Four dominant types of strong wind events, correlated with respective meteorological situations, are listed below. 
Poland
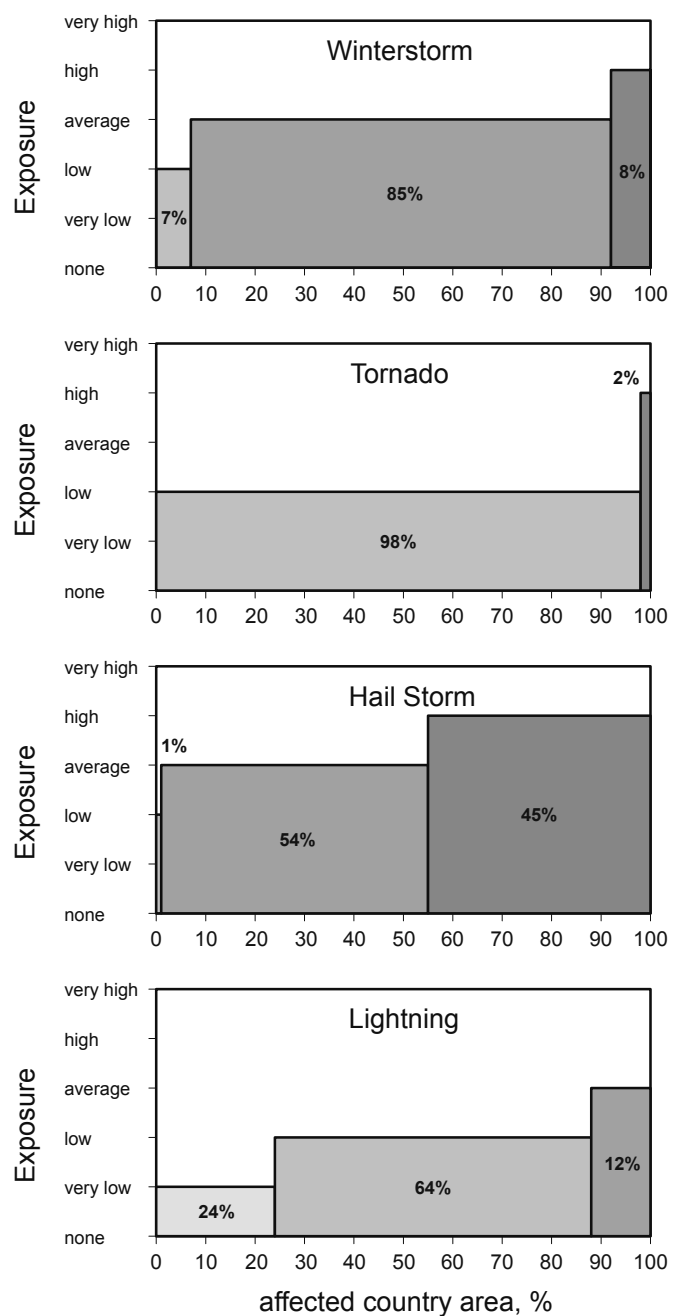

South Africa
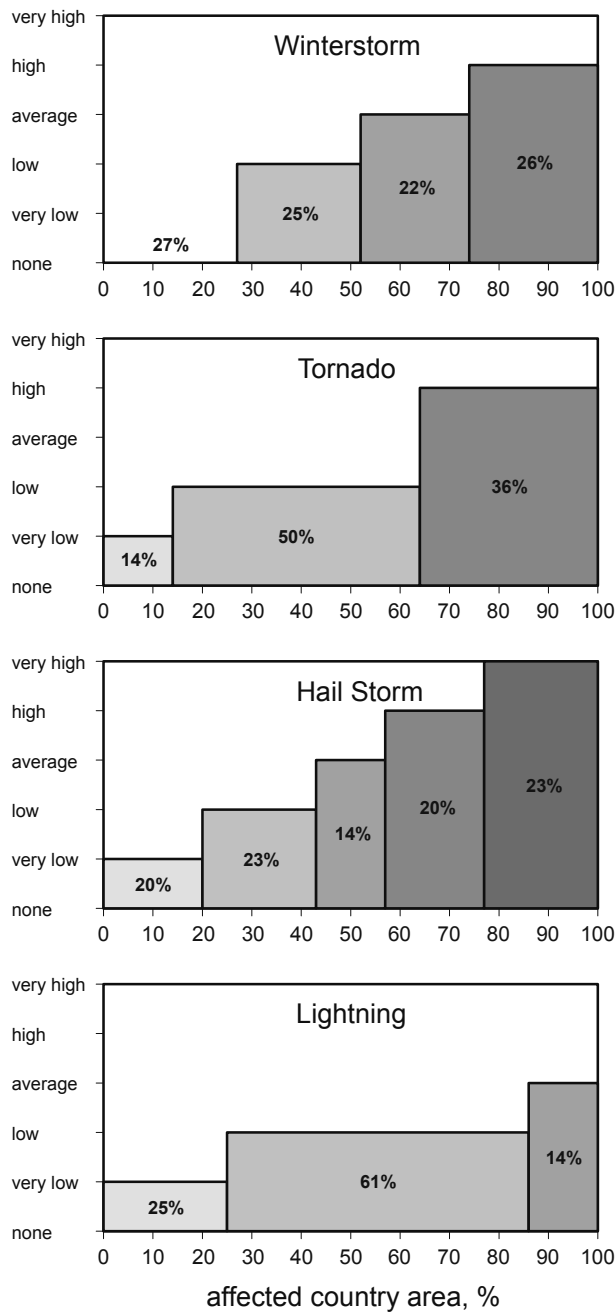

Fig. 2. Comparison of climatic risks of Poland and South Africa.

- Frontal storms (western or northern-western extra-tropical cyclones) generated in cold seasons by deep low pressure, typically approaching from the west or northwest and characterised by strong wind speeds.

- Foehn winds due the low pressure systems travelling northwards with the air movement over the southern orographic (mountainous) barrier, especially in the Tatra Mountains. These result in strong southerly winds, limited to relatively small geographic regions. 
- Thunderstorms, the related large-scale gust fronts and possible high intensity events. Also localised medium-scale downbursts, small-scale microbursts and other straight-line winds (derechos), which are related to profound atmospheric instabilities - often associated with intense thunderstorms.

- Tornadoes - localised events of extreme nature conditions.

Passages of large frontal events can be well documented due to the network of the meteorological stations of the Institute for Meteorology and Water Management. An example of such records is demonstrated in Figure 3, which presents a diagram of the maxima of gust wind speeds recorded during cyclone Kyrill, which developed over Europe between 17 and 19 January 2007 (Fink et al. [17]). This cyclone is commonly regarded as the most devastating wind event in Poland within the past 20 years (Żurański et al. [56]). On the night of 18 January, the country was affected by a 400 $\mathrm{km}$-wide front which generated a series of thunderstorms, straight-line winds and tornadoes (confirmed by bow-echo signatures detected on radar images). At the peak of the storm, the difference in atmospheric pressure between the north and south of Poland was nearly $30 \mathrm{hPa}$, which is significant.

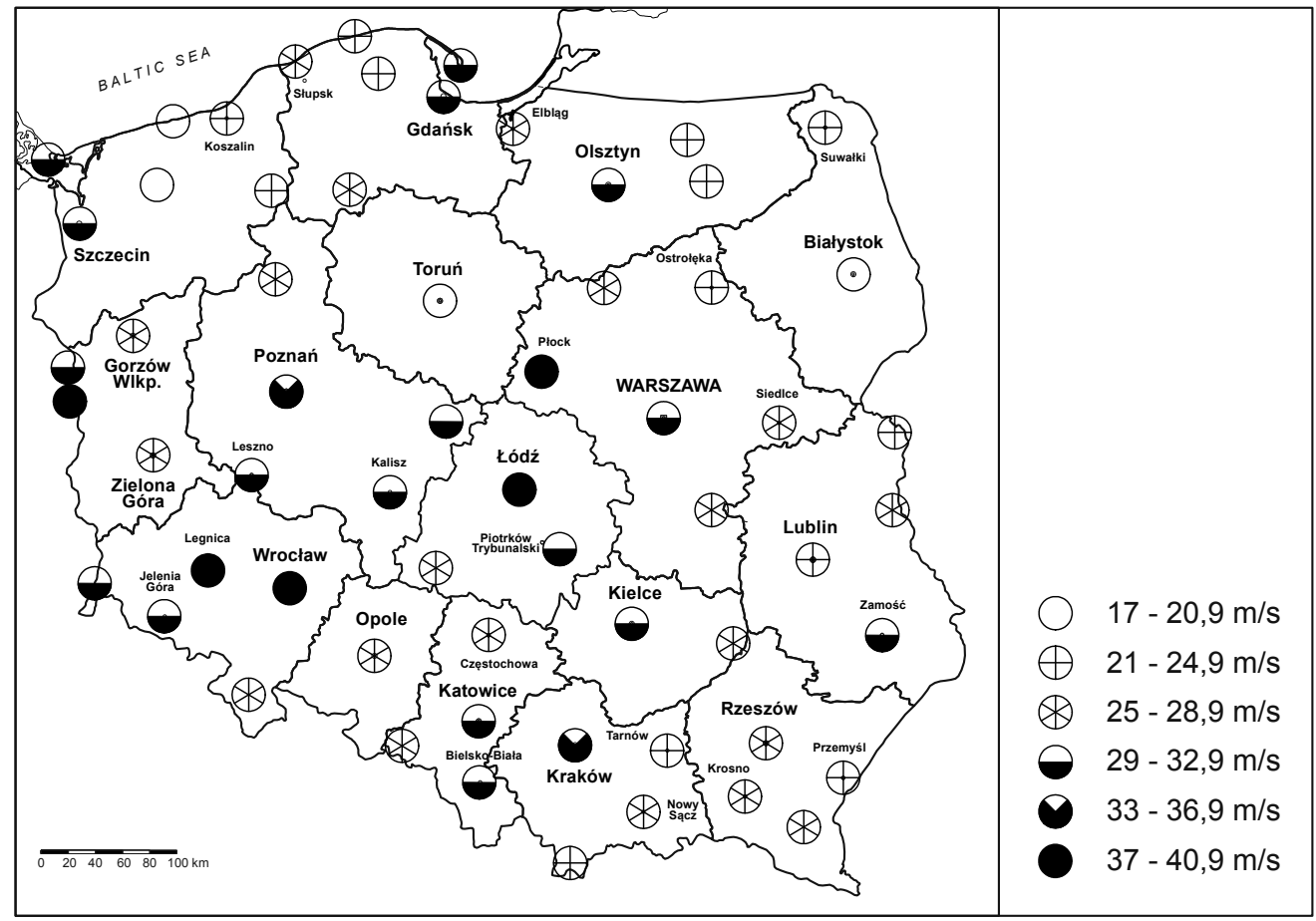

Fig. 3. Maxima wind speeds recorded in Poland during the passage of cyclone Kyrill, 17-19 January 2007 (Fink et al., 2009). 
The prevalence of extreme wind speeds generated by winter storms, in defining the design wind input parameters for Poland, can be demonstrated on the basis of the data obtained from a wind speed recorder located in Sulejów, (in the central - southern Poland, between Łódź and Częstochowa). Figure 4 presents the yearly maxima gust wind speeds recorded between 1973 and 2005. The gust wind speeds reached $34 \mathrm{~m} / \mathrm{s}$ on three occasions only. All these events were generated by low-pressure fronts approaching from the westerly direction, for which the exposure of the meteorological station is totally open (i.e. in compliance with the WMO specifications).

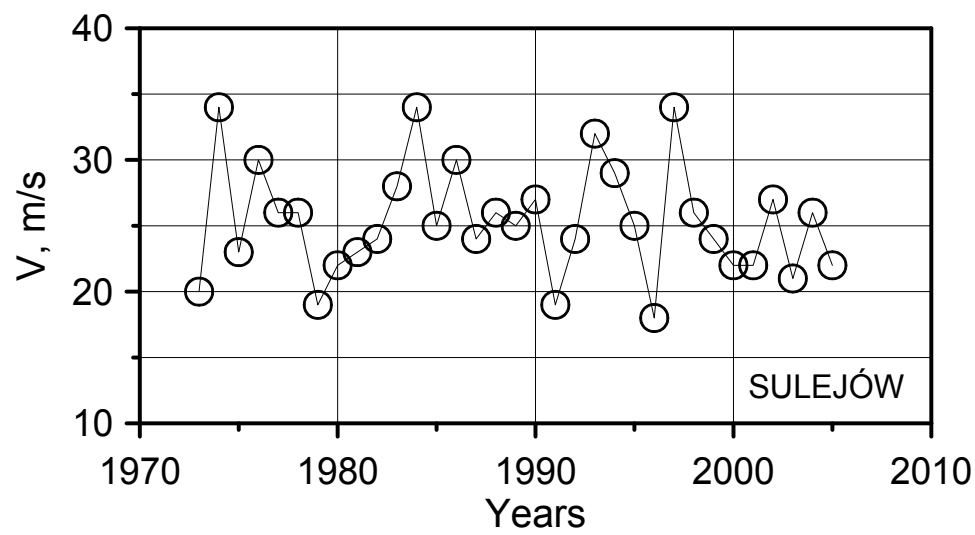

Fig. 4. Annual maxima of gust wind speed recorded at the Sulejów meteorological station.

The corresponding Gumbel probability distribution of the maxima of yearly gust wind speeds is presented in Figure 5. The straight line of the Gumbel theoretical distribution was fitted by using the maximum-likelihood method.

The wind speed corresponding to a 50 -year return period is about $37.5 \mathrm{~m} / \mathrm{s}$, which is higher than the value of $34 \mathrm{~m} / \mathrm{s}$ quoted above, but smaller than the value of $41 \mathrm{~m} / \mathrm{s}$, discussed in relation to the Eurocode (i.e. including the partial loading factor).

A similar analysis was undertaken for the data from selected 40 meteorological stations over the entire country (taking into account terrain effects). In this analysis, 10 minute mean wind speeds from 12 directional sectors were considered. The results of the analysis were used in the development of a wind map for the National Annex to Eurocode 1-4 [16]. (Similar analysis for the gust wind speeds was also carried out.)

Results are presented in Figures $6 \mathrm{a}$ and $6 \mathrm{~b}$. In these figures two histograms are presented of the reduced frequency of occurrence of the yearly maxima of gust wind speeds recorded between 1960 and 2005 (including some discontinuities before 1980s). The reduced frequency refers to a reduction process in which the number of 
occurrences of a particular wind speed was normalised by the total number of events in each group.

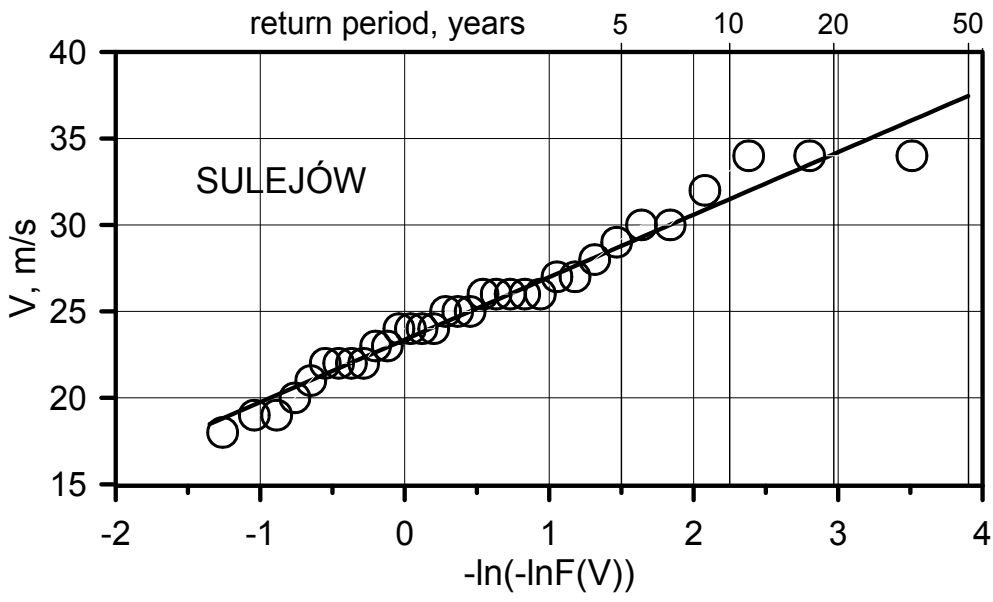

Fig. 5. Gumbel probability distribution plot of the annual maxima gust wind speeds recorded at the Sulejów meteorological station

Figure 6a depicts the histogram of 107 events classified as thunderstorms (together with the respective probability distribution function). In Figure $6 \mathrm{~b}$ the histogram of 804 winter storm events and the respective probability distribution are included. Figure $6 \mathrm{~b}$ also accommodates a 'prorated' probability distribution taken from Figure 6a (for comparative purposes). Despite some differences the two histograms are fairly similar. The average maxima due to frontal low systems were calculated as $25.4 \mathrm{~m} / \mathrm{s}$ and $24.9 \mathrm{~m} / \mathrm{s}$ for thunderstorms. The maxima values were $38 \mathrm{~m} / \mathrm{s}$ and $40 \mathrm{~m} / \mathrm{s}$, respectively. The probability distributions corresponding to both types of events are almost identical.

Of interest is that for the period of 45 years, seven times less wind speed maxima were generated by thunderstorm than those relating to low-pressure systems. This could be due to the relatively short summer season (i.e. the possibility of the development and the duration of convective conditions) and also the issue of the smaller spatial extent of thunderstorms, in which individual events may not be able to be detected (recorded) by the network of meteorological stations in the area of concern.

Most devastating wind events in Poland are tornadoes. It has to be noted however, that in some cases the damage reported in the media to have been inflicted by tornadoes was in fact due to other types of extreme wind events like downbursts or straight-line winds (derechos). 
a)

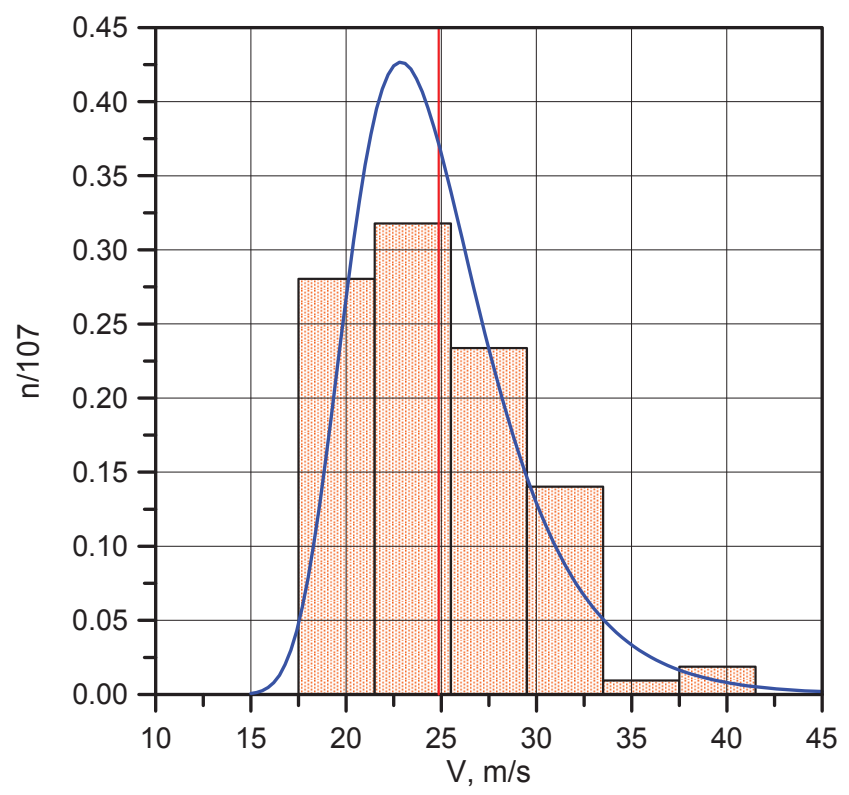

b)

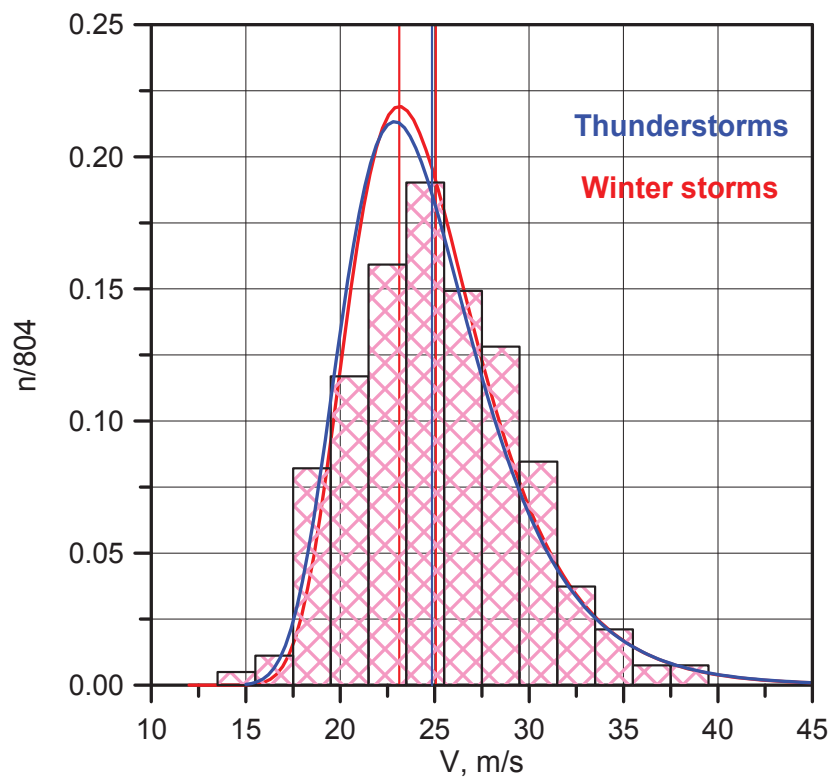

Fig. 6. Histograms of the frequency of occurrence of the yearly maxim gust wind speed due to strong wind events recorded from 23 meteorological stations between 1960 and 2005; a) 107 thunderstorms, b) 804 winter storms (Project R04 001 02, 2010). 
Figure 7 presents the geographical distribution of tornadic events, which occurred between 1979 and 1988. This map was developed on the basis of a search and analysis of media reports (Lorenc [35]). In total 42 events were identified (i.e. an average of four events per year), with the actual number of events varying between one and seven. Similar information transpires from Dotzek [15]. The spatial distribution of tornadic events is fairly uniform, with fewer events taking place over the northern/coastal regions of the country.

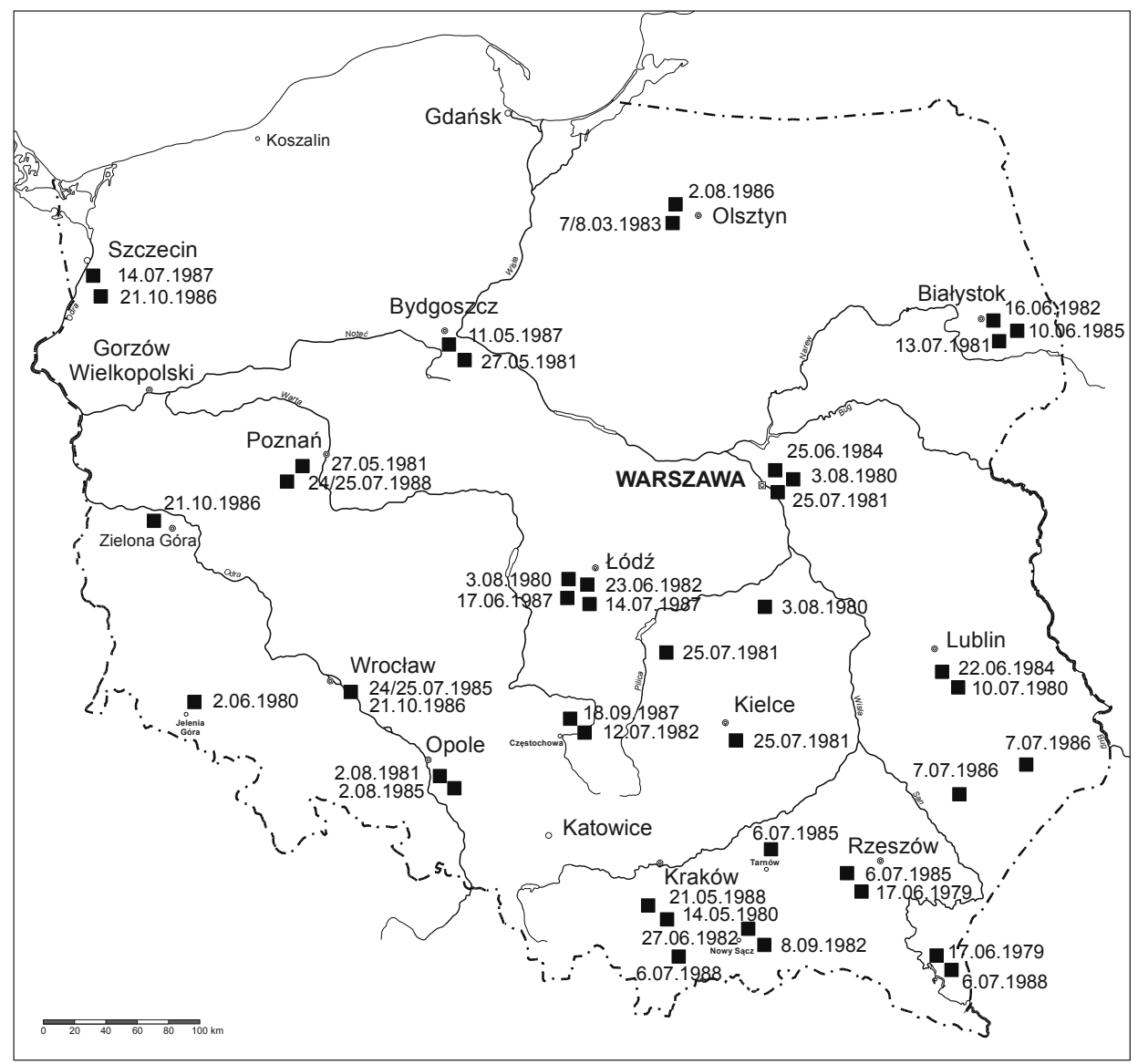

Fig. 7. Geographical distribution of tornadic events in Poland between 1979 and 1988 (Lorenc, 1996).

The damage associated with these events was significant although of a limited spatial spread. The most significant were devastations of forests due to an event in 2002, and the damage swath in the Częstochowa region which annihilated more than 250 building structures. The corresponding wind speeds were estimated to have exceeded $69 \mathrm{~m} / \mathrm{s}$ (Chmielewski et al. [6]). 
Figure 8 presents monthly distribution of the tornadic events from 2000 to 2011 . It can be seen that the vast majority of these take place between May and August, which correspond to summer season thermal instabilities and the development of severe thunderstorms.

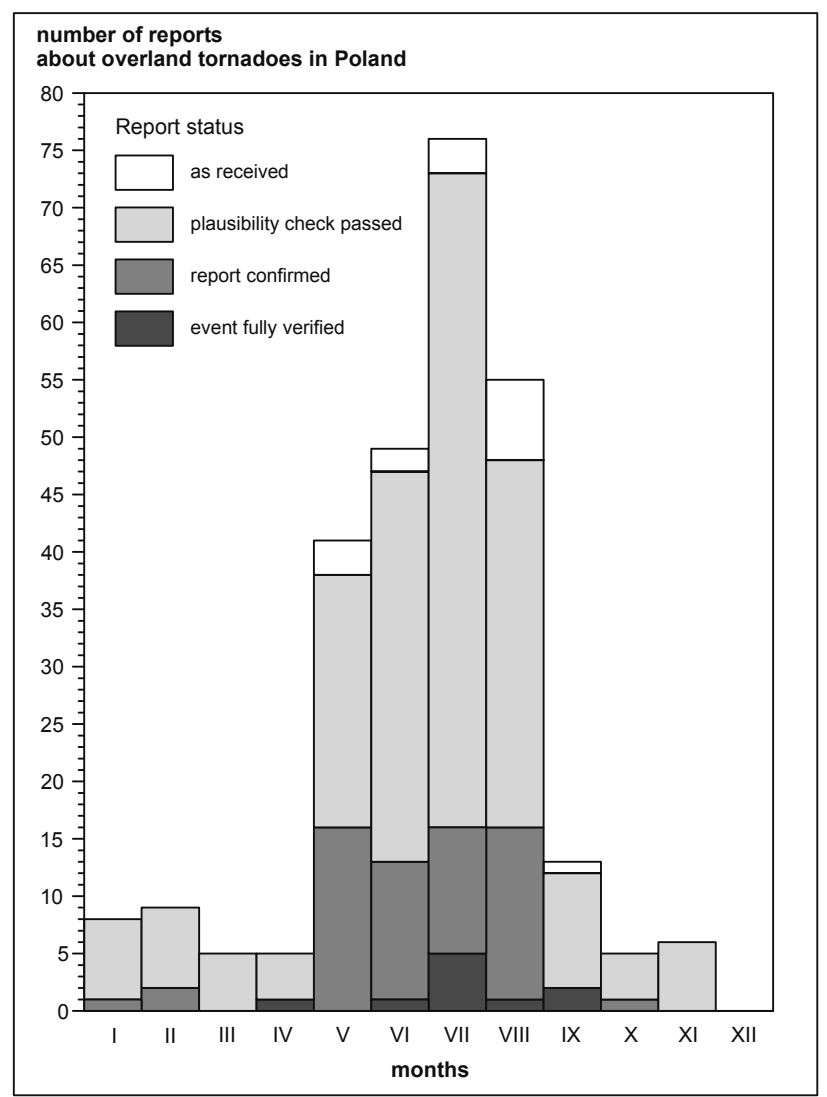

Fig. 8. Monthly distribution of tornadoes in Poland in the years 2000-2012 (based on data from ESSL - ESWD).

In general, it is not possible to combine the probability distribution of extreme winds generated by tornadoes with those based on historical wind records due to frontal winds and thunderstorms. This is in view of the differences of several orders of magnitude in the probability of occurrence, which require a geospatial statistical approach. Such an analysis has been undertaken by Goliger et al. [19] for South Africa and it has been shown that, due to an extremely low probability of occurrence, tornadic wind speeds become relevant only in certain parts of South Africa and for elongated structures like transmission lines. Similar estimations were performed in the USA (McDonald [37]). 


\subsection{South Africa}

The southern portion of the African continent has a diverse climate. South Africa alone is characterised by 24 climatic zones, ranging from arid desert areas to the tropics, with dominant zones of hot desert, dry grassland and subtropical. Two major types of severe windstorms affect the country, namely frontal (typically in coastal regions) and inland, typically due to convective activity. A proposed division of the country into six zones experiencing strong wind events has been presented in Goliger and Retief [22].

Strong inland winds are of a localised nature and originate typically as a result of severe convective activity. Frontal winds are due to large, low-pressure systems that produce mature storms. In Figure 9 two of the zones - which are of most relevance to the design, construction and distribution of the human habitat in South Africa - are presented. These zones are known to be subject to the most adverse wind conditions and damage in the country.
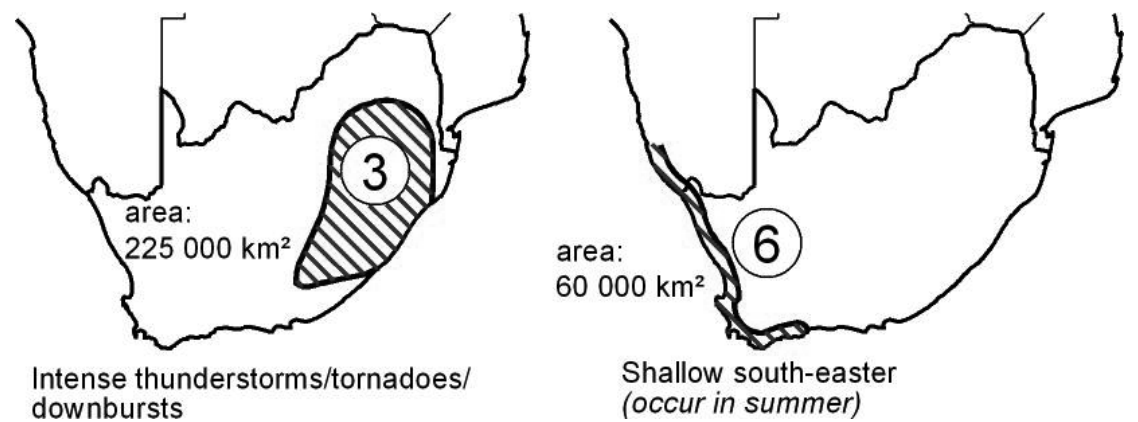

Fig. 9. Zones of intense thunderstorms and shallow south-easters.

The occurrence of extreme wind conditions is associated with the intense thunderstorms that develop in the form of super-cells or squall lines. These events are also known to produce localised extreme wind phenomena, namely tornadoes and downbursts. Although the geographical extent of downbursts and tornadoes is very small (typically less than a few $\mathrm{km}^{2}$ ) in relation to intense thunderstorms (with an area in the order of $2000 \mathrm{~km}^{2}$ ), they can generate extreme winds in excess of $50 \mathrm{~m} / \mathrm{s}$. Figure 10 presents a map of the mean rate of occurrence of tornadic events in South Africa.

The probability of wind speed occurrence represents the number of times within a stipulated time period that a wind speed of a certain magnitude will occur in a certain area. This information is usually derived from a statistical analysis of the data obtained from recording instrumentation placed within the area. Various extreme value distribution techniques can be used (e.g. Pareto, extreme Type I and Type II, Weibull). An example of such a distribution is presented in Figure 11 for the annual maximum hourly mean and peak gust wind speeds in Cape Town (Milford [38]). 


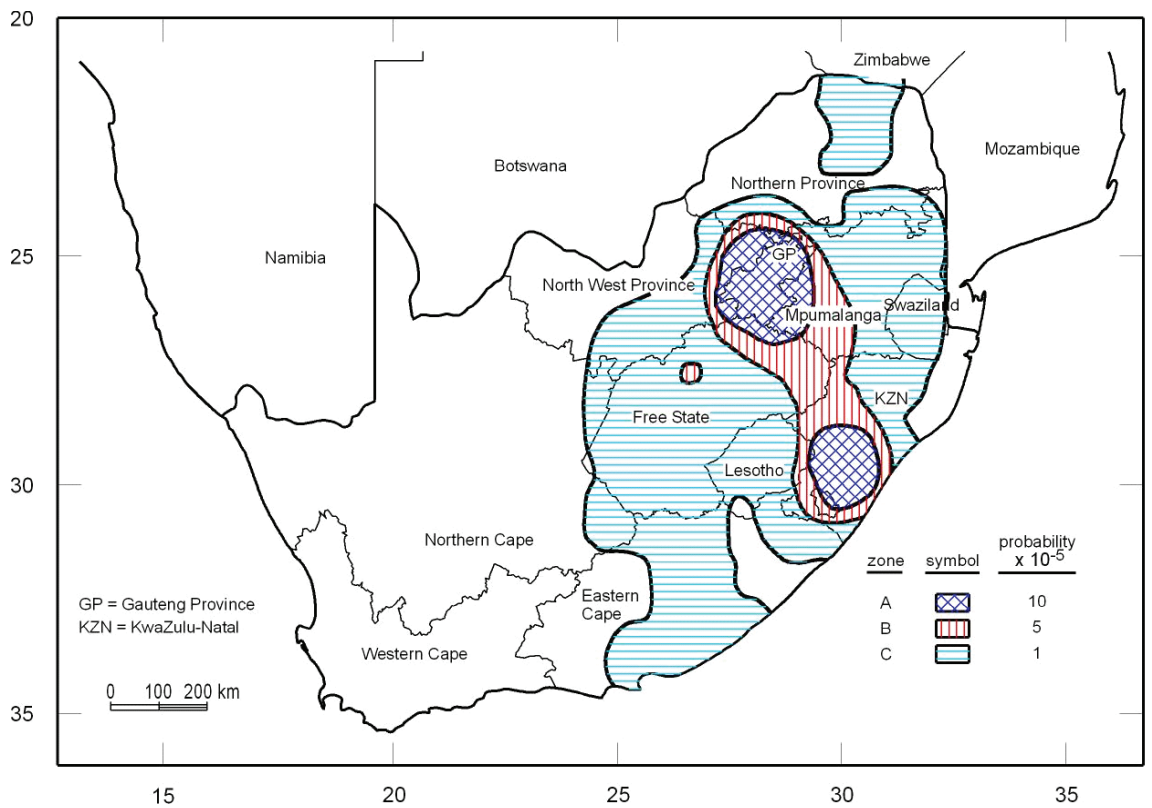

Fig. 10. Mean rate of occurrence of tornadoes, excluding events with an intensity of F0.

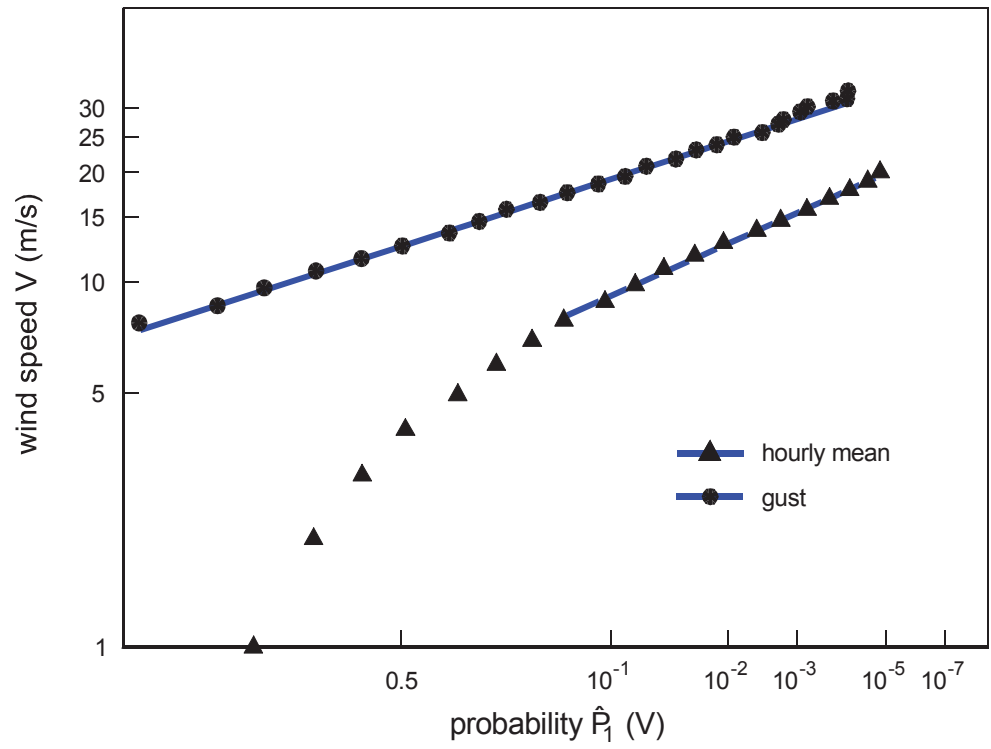

Fig. 11. Probability distribution of mean and gust wind speeds for Cape Town International Airport (Milford, 1987). 
The above approach assumes that large geographic regions are homogenous and that the probability of the wind speed occurrence derived for a specific location is also applicable to other locations within the region. This philosophy forms the basis for wind loading design, where the loading for a structure is calculated using wind speeds obtained from an extreme value analysis for various return periods.

A recent detailed re-analysis of the wind climatic data for South Africa, which in the future will form the basis for a new map of the basic design wind speeds, has been carried out as a joint effort between the South African Weather Service, the CSIR and Stellenbosch University, leading to a PhD dissertation of A Kruger [33], a co-author of this paper. This dissertation considers several aspects of wind climatology, identifies six typical mechanisms generating strong and extreme winds, undertakes various types of extreme value analyses of the data from nearly 100 weather recorders, and compares the differences between these methods. Finally, the maps of the two to three-second gusts and hourly mean wind speeds with 50-year return periods are developed.

It is of interest to note that due to the complexity of the South African wind climate the classical extreme value distribution approaches (e.g. Gumbel - Fisher-Tippet Type I) are often not able to provide an adequate, statistical description of the magnitude of the extreme wind speeds. This is because in a mixed strong climate the data sets of extreme wind events contain values from more than one population of events.

This issue is demonstrated in Figures 12a and 12b, in which the annual maxima gust and hourly mean wind speed distributions for Robben Island (outside Cape Town) are compared. The extreme wind speeds at this weather station originate from two types of events, namely the passage of a cold front and the ridging of the Atlantic ocean high pressure system. Gumbel distribution was applied to each type of the events independently and also to all the data, i.e. under an assumption of a single type climate. These were then compared to a graph obtained from a mixed distribution method proposed by Gomes and Vickery [26]. It can be seen that the differences between the various distributions are substantial.

The information obtained from the extreme value analysis, as discussed above, formed the basis for the development of contour maps of the geographical distributions of the mean and peak gust wind speeds in South Africa. This process required an indepth spatial analysis and demarcation of the climatic regions, topographical features, and correlation of the wind speed and other climatic data - and will not be discussed in detail in the current paper. The resultant map of the 1:50 year maximum hourly mean wind speed is presented in Figure 13. 
a)

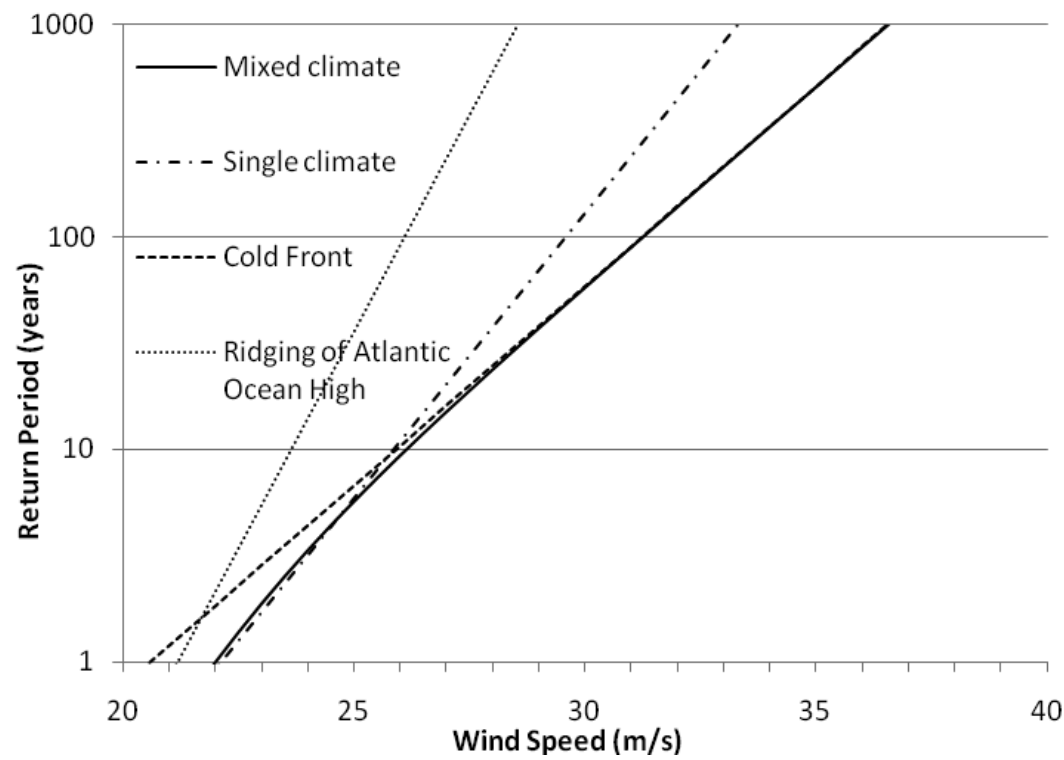

b)

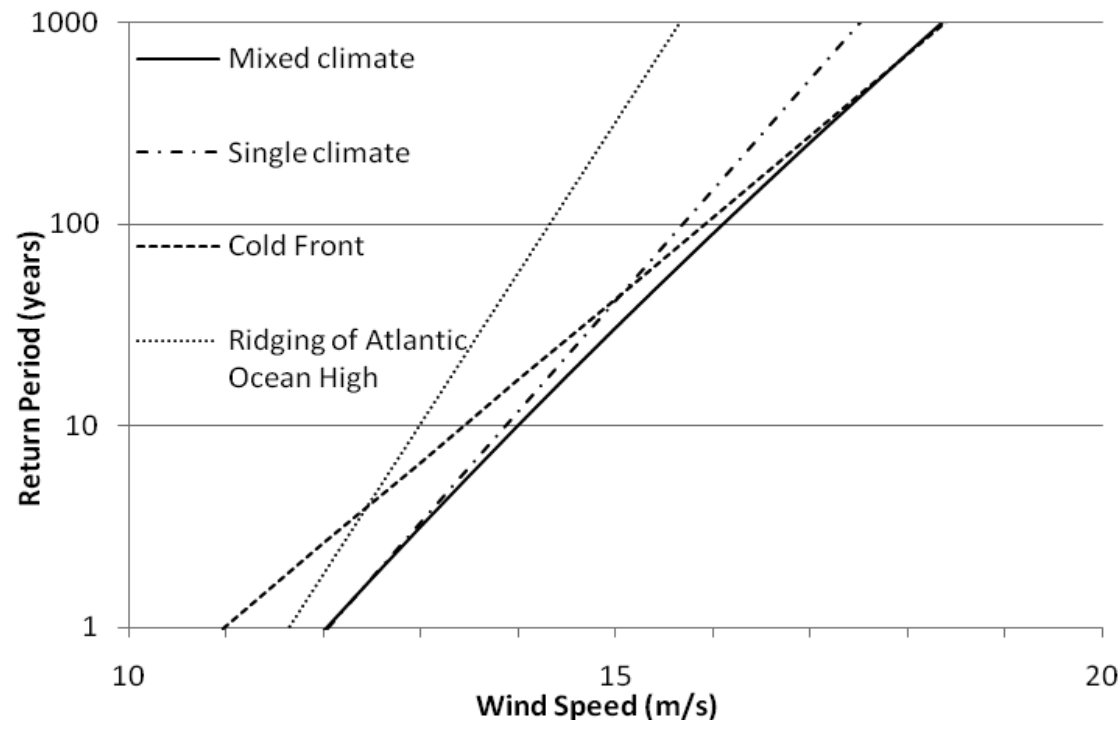

Fig. 12. Annual maxima distributions for Robben Island; a) peak gust wind speed, b) hourly mean wind speed. 


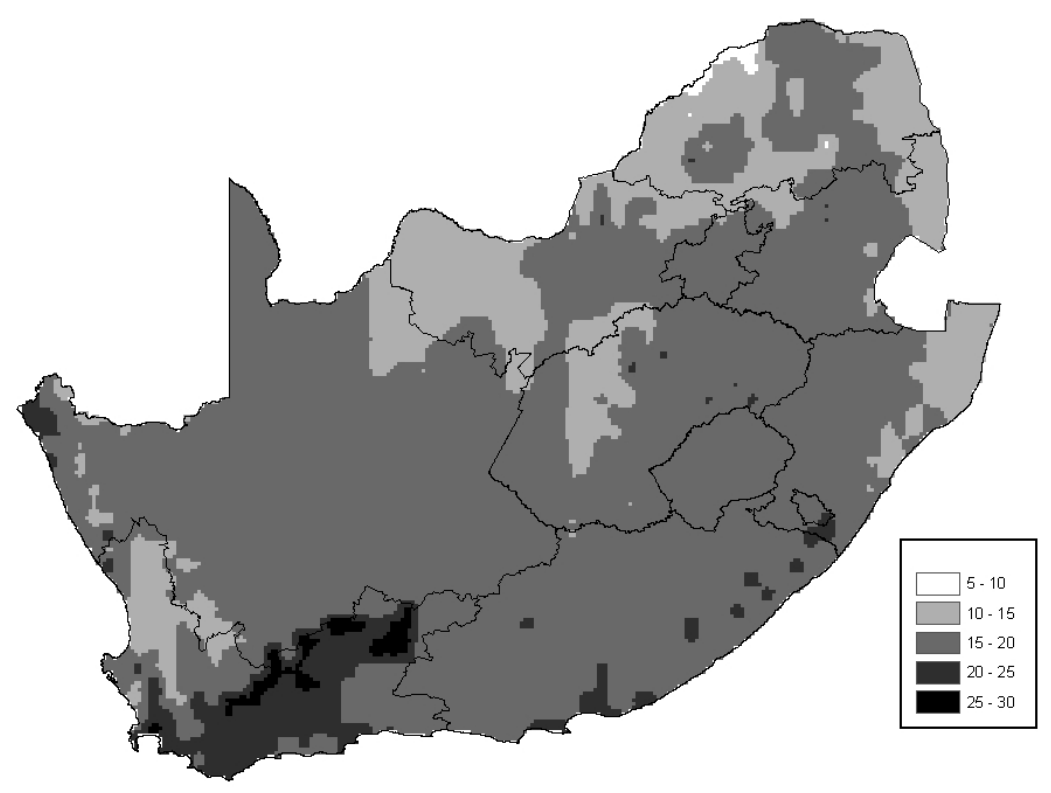

Fig. 13. Distribution of 1:50 year hourly mean wind speed for South Africa $(\mathrm{m} / \mathrm{s})$.

\section{Wind DAMAGE TO THE BUILT ENVIRONMENT}

As discussed in Section 2, the implications of wind damage to the built environment can be significant in terms of human and economical loss. In the following subsections a review of wind-related damage in Poland and South Africa is presented.

\subsection{Poland}

\subsubsection{Risk and statistics of damage}

As presented in Figure 2, almost the entire area of the country is at risk of the winter storms and tornado occurrences. Further information, related to Figure 2, is presented in Figure 14 (after Munich Re [40]) in which a comparison is made of the risks of occurrence of winter storms and tornadoes for 2006 and 2009. It is of relevance that both graphs indicate increases, both in terms of the rate of risks as well as the extent of affected areas. This issue demonstrates the need for updating the statistical data on the occurrence of the extreme design wind speed for the country, and may indirectly indicate an expected trend of increase in wind-related damage in the country.

In Poland there are few sources of the respective information, the most important being the data on building damage and collapse collected by the municipal, regional 
and provincial building control authorities, which are then collated by the Principal Office of Building Control (Główny Urząd Nadzoru Budowlanego; GUNB). However, this information covers a relatively short period of time - since the establishment of GUNB in 1995. Furthermore, only from 2006 a separate count of wind-related disasters was established; before that these event were generically classified as an "Act of God" (natural event).
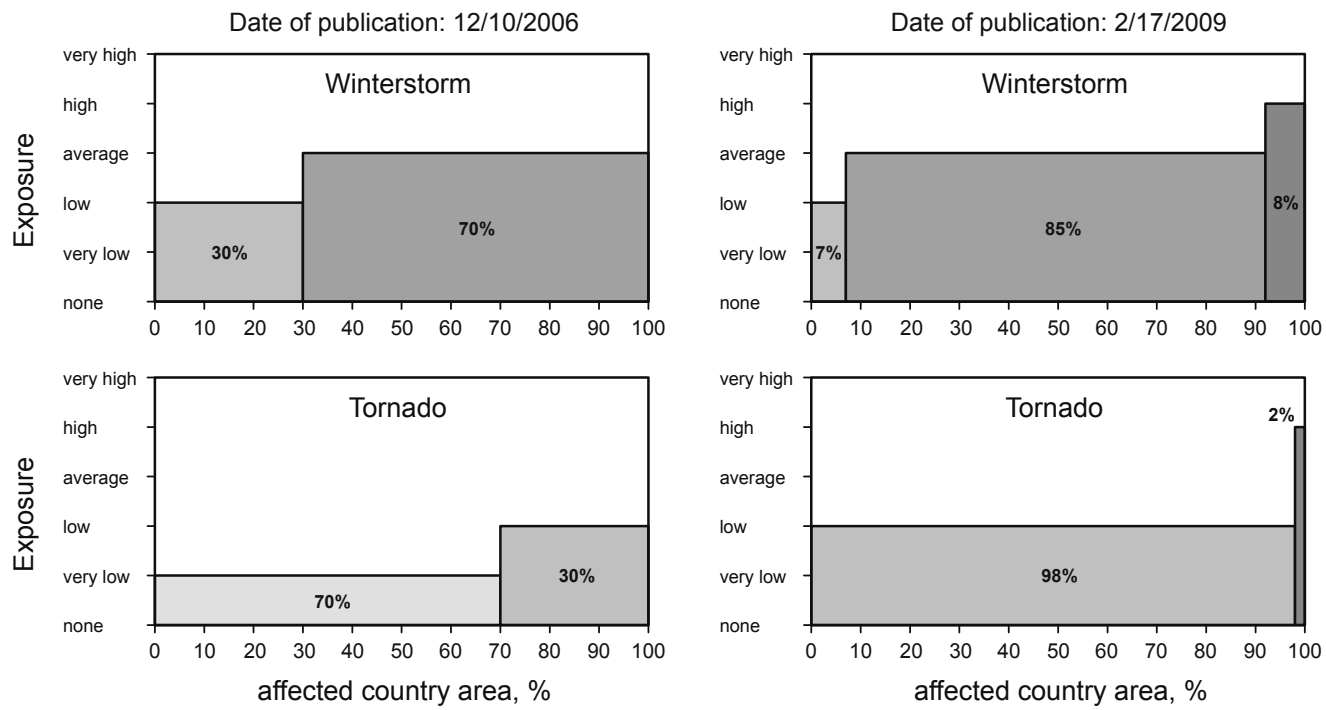

Fig. 14. Percentage of affected area and degree of exposure to winter storms and tornadoes for Poland.

Another source of information is the insurance industry. Historically, the only role player in this industry was the state insurance regulator (Powszechny Zakład Ubezpieczeń; PZU). This situation is useful in terms of accessing the relevant information, however, insurance was not compulsory and the threshold value of the wind speed, which was required for a successful claim, was $24 \mathrm{~m} / \mathrm{s}$ (10 in the Beaufort Scale) - probably in terms of the gust wind speed. Currently the insurance industry is deregulated and, in view of the number of agencies active in the market, collection of the data is far more difficult.

Other sources of information are media reports. Although access to this data is fairly time consuming this approach has been adopted by various researchers (e.g. Lisowski [34]). In the case of extreme wind events, which occurred fairly frequently in the past few years, it is also useful to access the information collected by local authorities and emergency services, which typically includes comprehensive photographic documentation posted on the internet. 
The damage to buildings caused by strong wind events is typically classified by GUNB as being an 'Act of God' and these constitute a significant majority of all events of this category (distinguished by GUNB only from 2006 [29]). In Figure 15 a comparison is made of the number of catastrophic 'Acts of God' between 1995 and 2011 [28, 29]. In 2007 (Bebłot et al. [3]) and 2008, tornado occurrences in the region of Częstochowa contributed to a substantial increase in the number of reported cases. In 2007, 401 out of 447 building collapses were caused by wind action, while 263 of them took place in the Czestochowa region, due to one event of 20 July 2007. It is of relevance to note that in the same year no damage was reported in the coastal regions, even though a series of strong storm events took place in autumn and winter. On the other hand, strong winter storms caused 59 catastrophic incidents in the Łódź province.

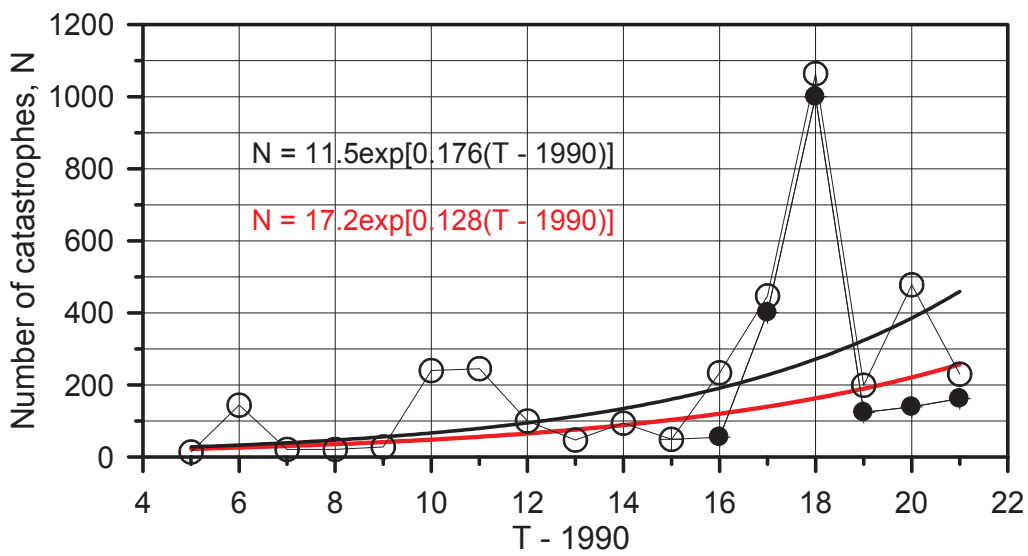

Fig. 15. The number of catastrophic events (GUNB); blank circles - all events classified as an 'Act of God'; black points: only wind damage. $\mathrm{T}-$ calendar year.

In 2008 - 1064 catastrophic damages classified as 'Acts of God' occurred and nearly 1000 of these were due to wind action. Again, these were mainly due to an outbreak of tornadic events on 15 August 2008, which caused:

- 534 catastrophic damages in the Łódź province (the districts of Radom and Piotrków Trybunalski;

- 237 in the Opole province (Strzelce district); and

- 17 in the Silesia province (Częstochowa and Gliwice).

On the following day strong winds resulted in 113 cases of catastrophic damage in the Podlasie province (the districts of Zambrów and Wysokie Mazowieckie). Apart from two strong tornados in 2007 and 2008, the yearly number of buildings destroyed by wind does not exceed 200 (Figure 15).

An attempt of quantifying the costs of various events classified as being an 'Act of God', including wind events, was undertaken by Lisowski [34]. An analysis of the data 
from PZU indicates that between 1960 and 1986 most of the damage to building structures was categorised as being 'small', in which the amounts paid out were less than $1 / 3$ of the original value of the building (Lisowski [34]). During this time there were few wind-induced collapses but these did not affect the general trend.

Lisowski also undertook an analysis of media reports between 1960 and 1990 by accessing more than 9500 issues of a daily newspaper Życie Warszawy. A total of 601 reports of wind damage was identified. These included:

- power and telephone lines (about 19\%),

- disruptions in fishing industry activities (about 17\%),

- devastation of forests (15\%), and

- damage to buildings was only less than $8 \%$ (6th position in the ranking of wind damage, which is surprising).

The monthly distribution of occurrence of wind damage events, elaborated and based on Lisowski's paper, is presented in Figure 16. It indicates that about $70 \%$ of damaging winds are related to cold seasons between mid-October and mid-March. (NB. Most strong thunderstorms and tornadoes develop in summer months, i.e. July and August, followed by June and May - Figure 8 and Żurański et al. [55]).

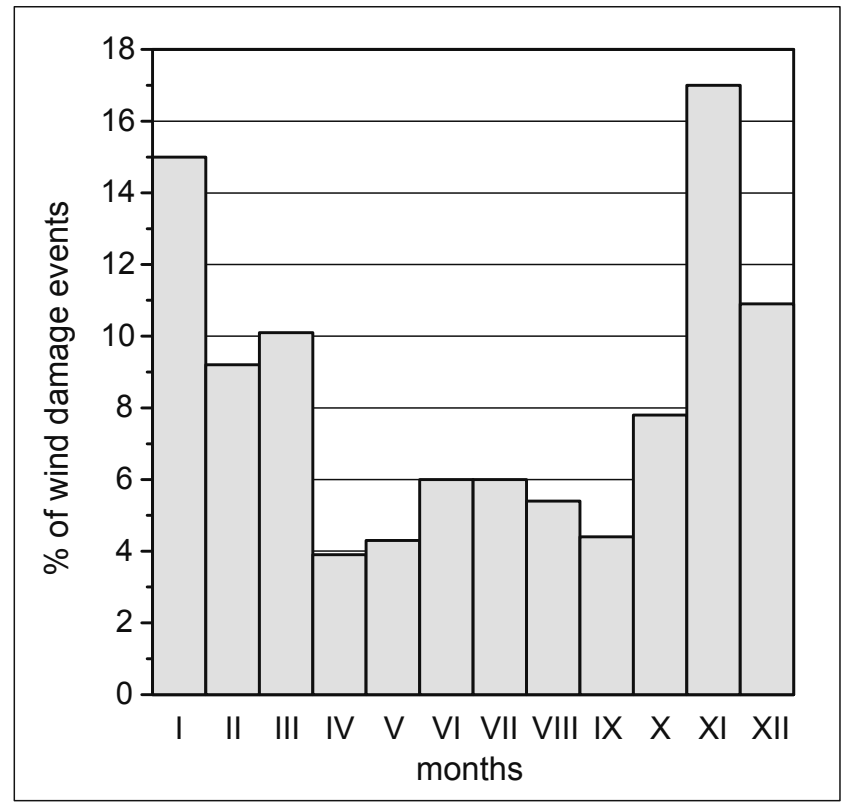

Fig. 16. Monthly distribution of loss (Żurański et al. 2009a according to Lisowski 1993). 


\subsubsection{Examples of damage}

Damage to buildings and other structures, which occurs in Poland, can be grouped generically into the following categories:

- overturning of boundary walls,

- deformation (or detachment) of information boards, antennas etc.,

- tear-off gutters, downpipes and flashings,

- deformation of railings and balustrades,

- damage to glazing, window/door frames, collapse of gates and garage doors,

- removal of the thermal insulation of walls and roofs,

- local damage to roof covering and related flashing,

- damage or removal of roof sheathing,

- damage to structural components of roofs,

- removal of entire roofs,

- damage or loss of exposed structures/elements e.g. towers, chimneys, church spires,

- collapse of gable walls (at attic level),

- collapse or uplift of attic floors,

- partial loss of stability, fracture, puncture or collapse of external cavity walls, and

- collapse or removal of utility poles.

Figures 17 a to $17 \mathrm{~d}$ include images of typical damage.

It is important to investigate and analyse details of the damage in terms of the type of structures, their age, structural systems which were implemented, detailing, type of materials, etc.

Post-disaster analyses and surveys typically indicate the selective nature of the damage which is often related to the structural robustness. For example, buildings without a concrete ring-beam integrating the walls at the roof-level, are much more vulnerable than those which include the ring beam. The same holds true for the protection of edges and exposed roof elements. Table 1 presents a summary of the extent of typical damage to buildings in Poland during a tornado event in the Łódź province in 2008 (Żurański \& Szer [54]). It can be seen that a substantial number of damage reports refers to roofs and structures of buildings and that the number of residential structures is similar to that of other types of structures.

Table 1

Statistics of typical damage (Żurański and Szer, 2009)

\begin{tabular}{|c|c|c|c|}
\hline $\begin{array}{c}\text { Type of structure } \rightarrow \\
\text { Type of damage } \downarrow\end{array}$ & Human shelter & $\begin{array}{c}\text { Other buildings and } \\
\text { structures }\end{array}$ & Total \\
\hline Insignificant & 193 & 125 & 318 \\
\hline Roofs & 126 & 108 & 234 \\
\hline Roofs \& ceilings & 10 & 11 & 21 \\
\hline Entire structure & 115 & 179 & 294 \\
\hline
\end{tabular}


a)

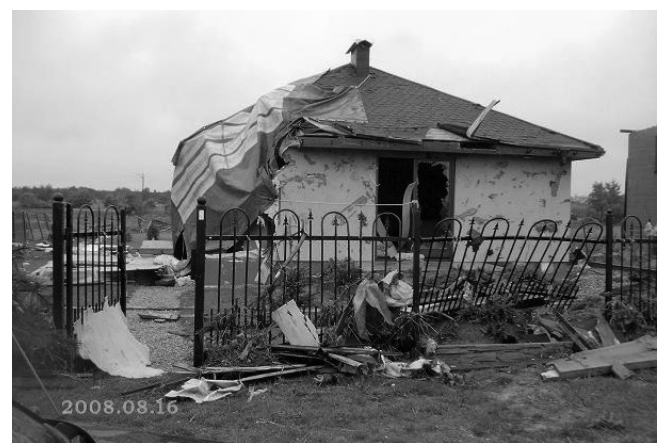

c)

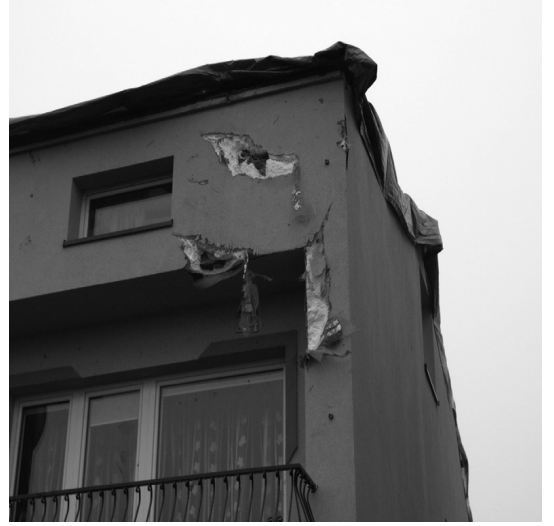

b)

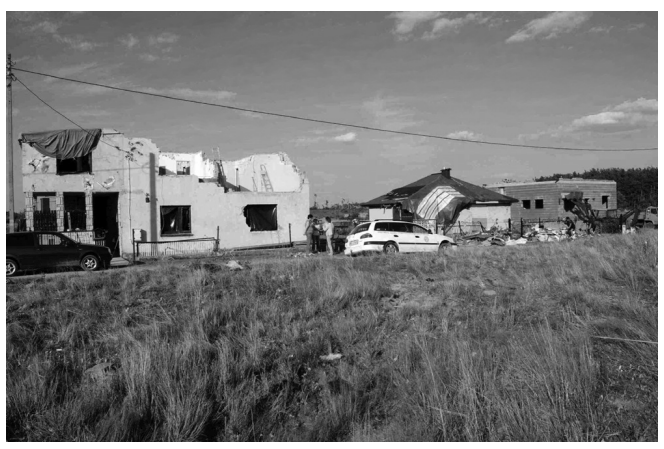

d)

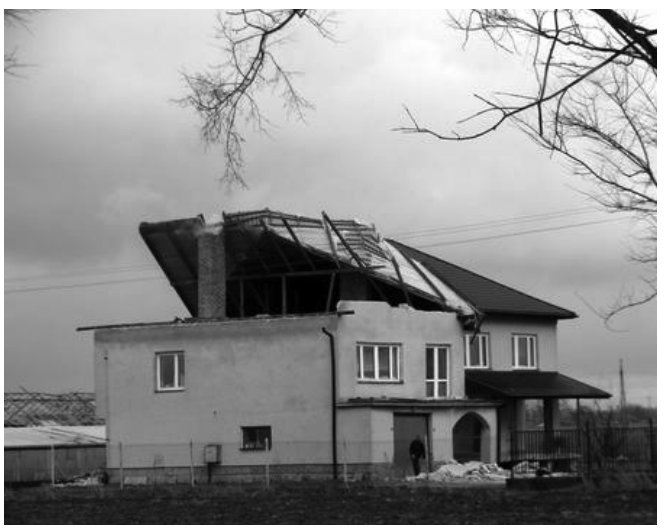

Fig. 17. Typical examples of damage to houses caused by tornados in Poland; a) damage to the building of frame construction, b) partial removal of the 2 nd storey of a building (Phot. G. Bebłot), c) damage to walls inflicted by windborne debris, d) failure of a sheet metal roof.

\subsection{South Africa}

\subsubsection{Extent of damage}

Most of the wind damage to structures in South Africa relates to human shelter and its surroundings although substantial damage to community, commercial and industrial structures was also reported over the years. An overview of the type and extent of the damage is presented below.

\section{Minor damage}

Minor damage is typically limited to roofs. Frequently it refers to the removal of a limited amount of tiles and localised uplift of roof sheeting, typically along the eaves and ridges. This enables immediate pressure equalisation and prevents further uplift. 
Although this has no structural implications, it can lead to permanent damage of ceilings and the contents of the house, if the storm is accompanied by rain. Examples of such damage are given in Figure 18.
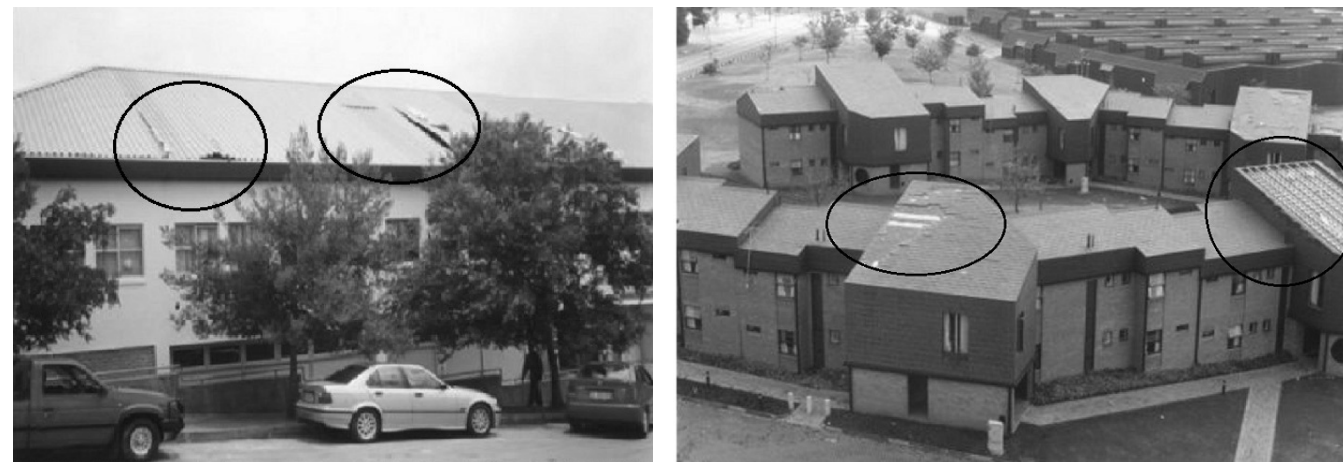

Fig. 18. Examples of minor damage to roofs in South Africa (circled).

\section{Substantial damage}

In certain cases, the action of severe winds can introduce significant damage to roofs and glazing. This is typically for sheeted roofs, as well as tiled roofs with a PVC underlay, which are fairly impermeable and prevent the equalisation of pressure. Under extreme winds this may result in significant damage to roofs including the failure of fixings, breakage and deformation of the entire sheeting and buckling of trusses. If the fixing of sheeting to purlins is sufficient, this may result in the destruction of parts of, or the entire roof structure. Examples of such damage are presented in Figures 19.
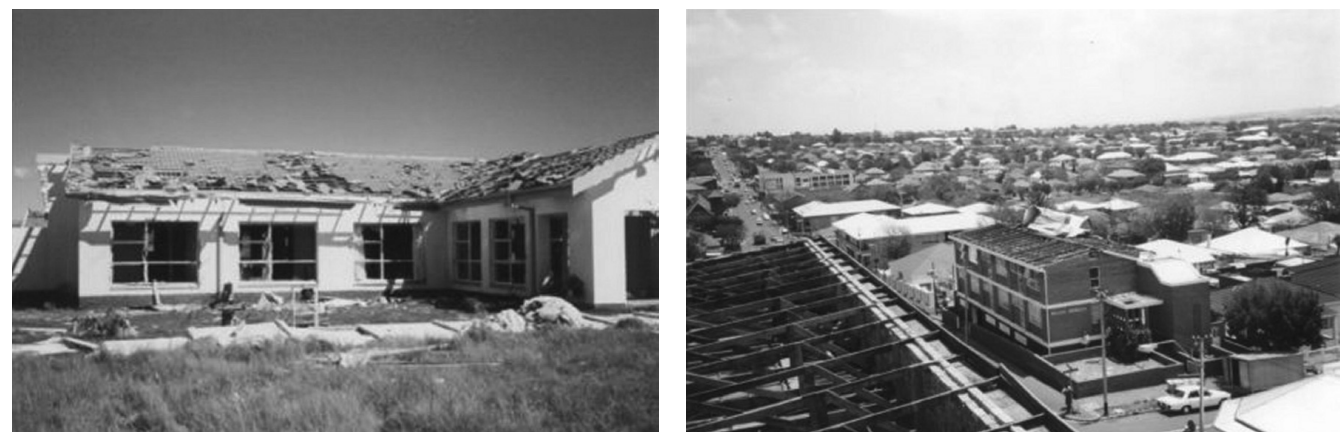

Fig. 19. Substantial damage in South Africa. 


\section{Serious damage}

Serious damage involves roofs, portions of, or entire walls (Figure 20). In some cases, the upper portions of the walls are ripped off due to the uplift force generated over the roofs and transferred to the walls via the roof ties. In other cases entire walls are blown over or sucked outwards (including concrete elements).

The extensive damage to the walls of buildings usually coincides with the total destruction of garages, outbuildings and garden walls as well as severe damage to municipal infrastructure which receives comprehensive engineering inputs in the design and construction process (e.g. road signs, street lamps and commercial structures).
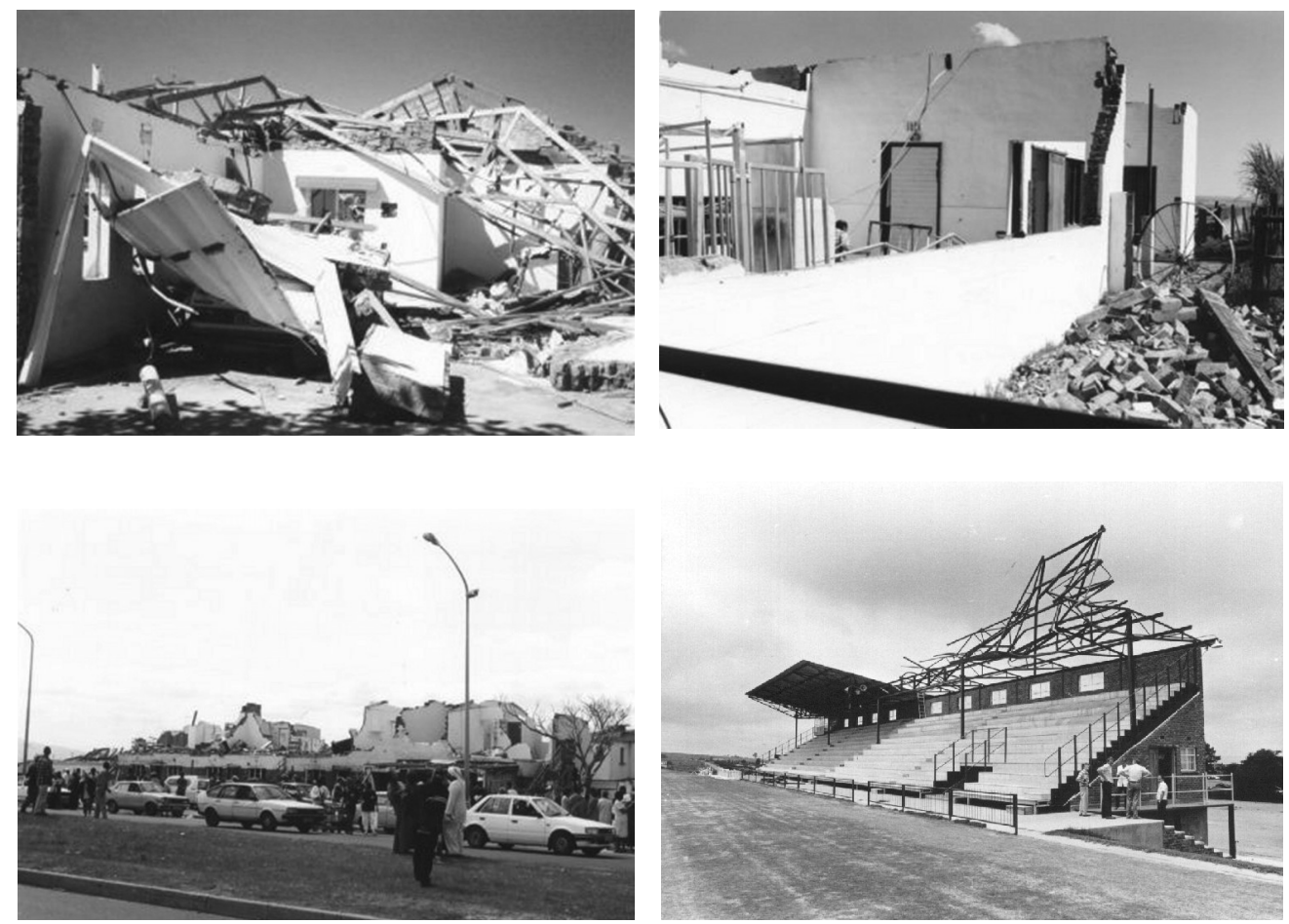

Fig. 20. Examples of serious damage in South Africa.

\section{Complete devastation}

In extreme cases, the total annihilation of a built environment, including housing structures, can occur. An example of the total devastation of an informal settlement due to the November 1952 Albertynsville tornado is presented in Figure 21. This tornado event crossed over the southern suburbs of Johannesburg, killing 24 people and injuring more than 600 . 


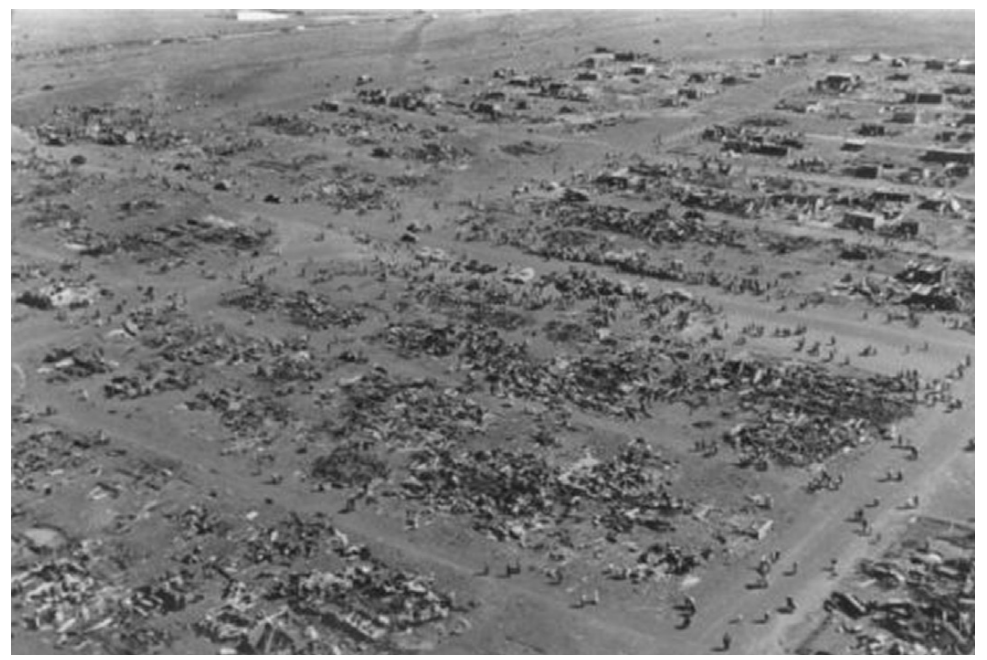

Fig. 21. An aerial view of the total devastation of Albertynsville township in South Africa.

\subsubsection{Statistics of damage}

A wind-damage database for South Africa has been developed at the CSIR, which includes records of about 1000 events, $30 \%$ of which are classified as tornadoes. The initial statistics of the database are presented in Figures 22 to 25. In Figure 22 a trend, where the number of wind-damage reports has increased since 1948, is evident. This could be attributed to the increase in population density (i.e. the density of human development), better administrative and reporting procedures, and possible climatic change.

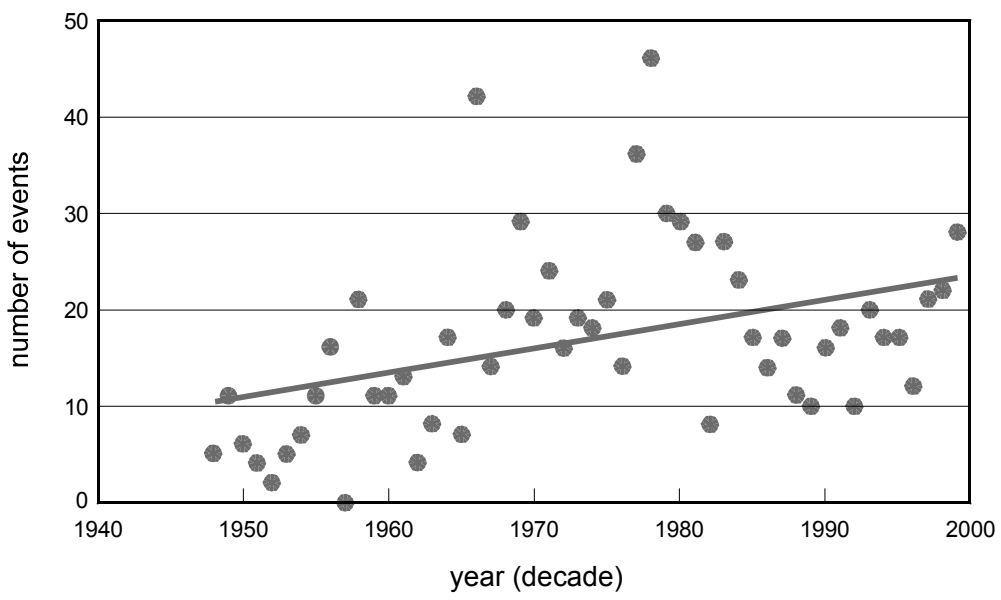

Fig. 22. Annual distribution of wind damage events. 
Injury and death due to windstorms seem to be on the increase (Figure 23), particularly during the past few years (1 400 people in the year 2000). About five devastating events affect human lives in a decade. The high number of injuries and deaths in the 1950-1960 decade was due to two large tornadoes. Descriptions of these events suggest that most loss of human life resulted from the direct failures of shelters (i.e. structures) and airborne debris originating from such structures.

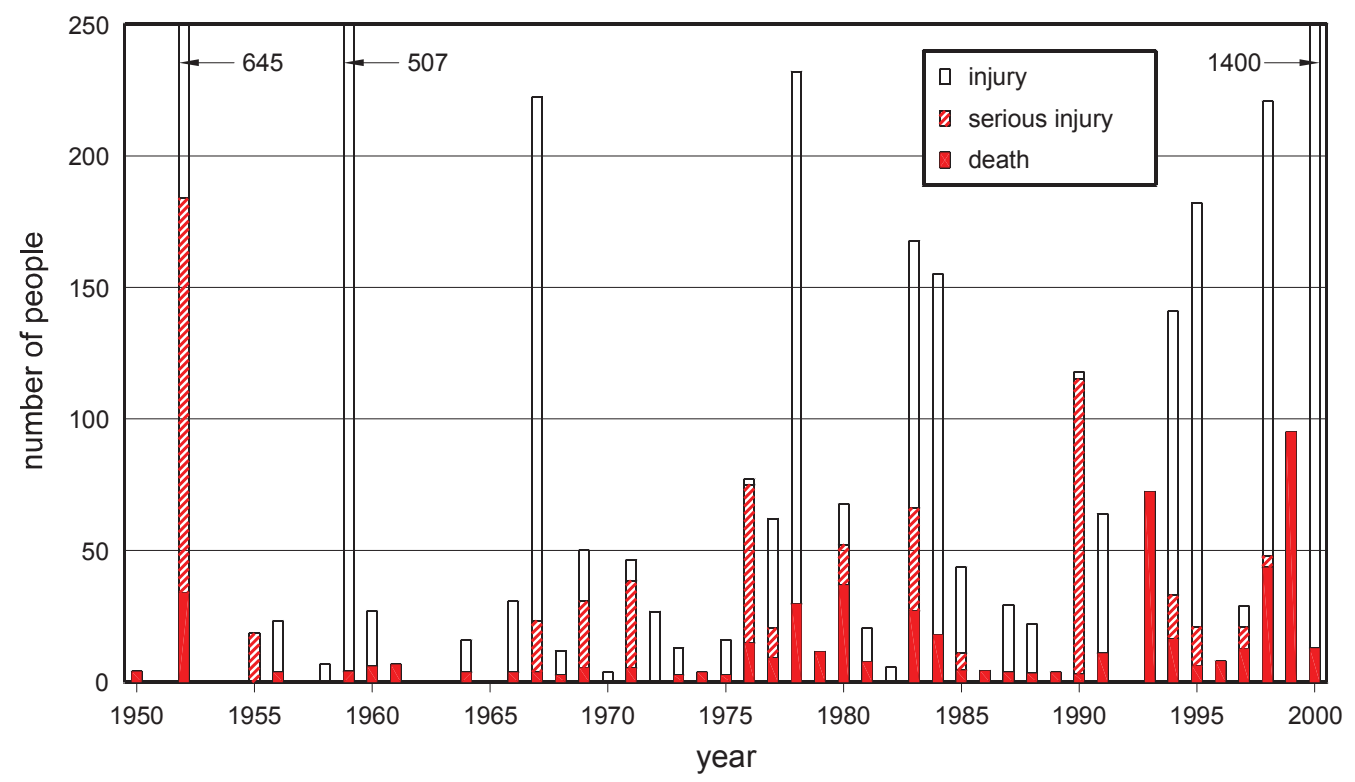

annual number of death, injuries, serious injuries

Fig. 23. Life and limb loss in strong wind events.

Figure 24 analyses the nature of damage with respect to various types of structures. It can be seen that about $70 \%$ of the reports included damage to houses and buildings, $30 \%$ to community structures and a similar percentage of damage to power and communication systems.

The information on damage to informal settlements is grossly underestimated, owing to poor communication and reporting systems, and further compounded by the historically inadequate coverage by the media. This statement is supported by the analysis of the number of people rendered homeless as a result of wind events shown in Figure 25. In recent years, with more attention being paid to underdeveloped communities, a significant increase in the number of homeless people has become evident. This is largely owing to better reporting on damage in areas of mass housing and informal developments. 


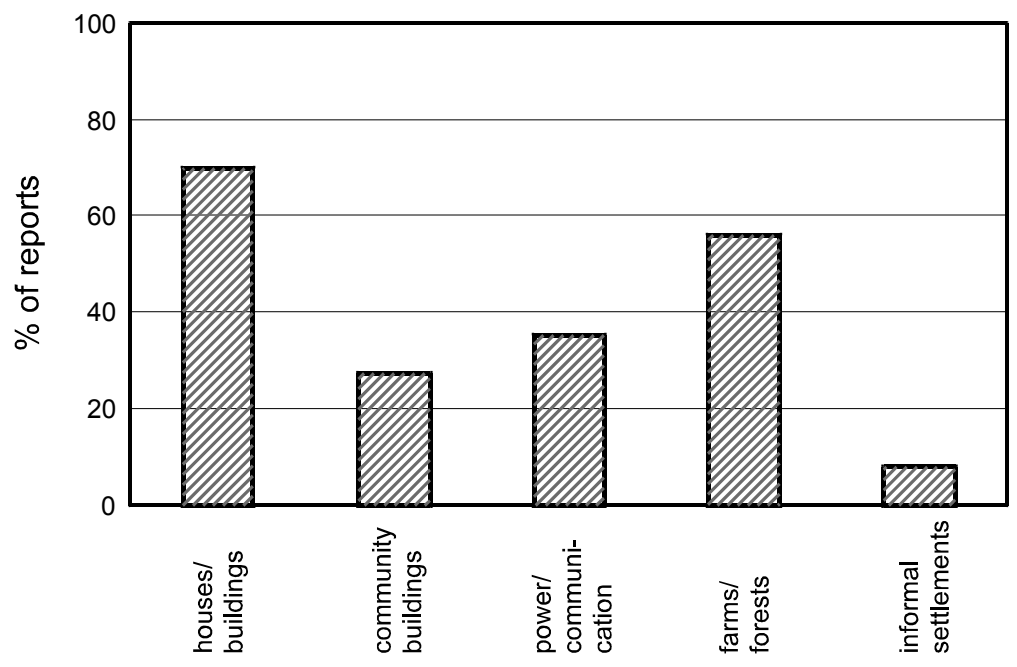

Fig. 24. Distribution of damage to various types of structures.

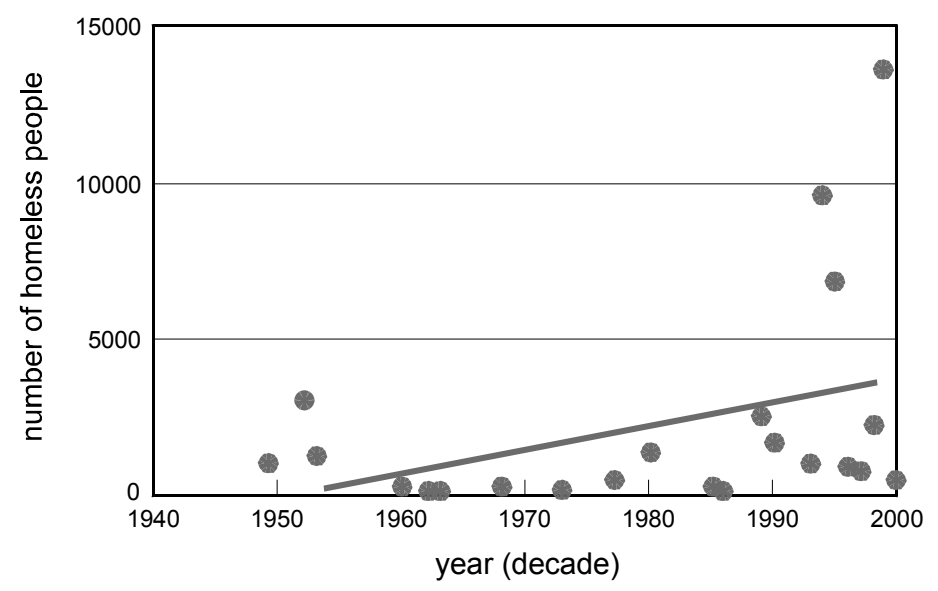

Fig. 25. Number of homeless people due to strong wind damages.

4. THE ROLE OF WIND LOADING DESIGN STANDARDS

\subsection{Applicability and COMPLiance}

From a design point of view, an optimal, if not the only, way to minimise the wind-induced damage to structures is to enforce a set of scientifically proven and probabilistically based, technical rules and regulations to be adhered to in the design process. Such 
design rules/processes are encapsulated in the design codification, which includes the primary aspect of loadings. The implementation of these principles should be viewed in terms of socially acceptable levels/extent of damage to the built environment.

Experiences from various countries across the world suggest that engineered structures which comply with the minimum design wind loading specifications can largely withstand severe climatic events. For example, Greenwood and Hatheway [27] report an analysis of the damage caused by Hurricane Opal in the USA, where less than $1 \%$ of structures conforming with structural standards was damaged. Cook [7] suggests that the actual damage to the built environment in the UK starts at wind speeds far below the design speeds stipulated in the code. Furthermore, the preliminary results of a survey undertaken by the Loss Prevention Council suggests that as many as half of all roofs of residential housing will fail at no more than half the design wind speed, i.e. at $25 \%$ of the design load (LPC [36]).

Walker et al. [49] claim that strict compliance with modern regulations and design codes in Australia has ensured that practically no damage to recent structures subjected to cyclonic conditions has been observed. Sparks et al. [47] mention that some carefully designed wood-framed houses at exposed locations experienced gusts in excess of $60 \mathrm{~m} / \mathrm{s}$ (during the 1989 hurricane Hugo) without sustaining any damage.

\subsection{Principles AND historical PERSPeCtive}

As with any loading that is considered when designing a structure, structural element or foundation, wind load is a statistical quantity. In particular, its variation with respect to time and space is pronounced. To cater for these properties, loading codes throughout the world developed individual systems of determining the nominal wind loads (which were subsequently combined with partial load factors and load combination factors).

In order to define the magnitude of the nominal loads, design codes have developed sets of consistent information on:

- the extreme winds (i.e. the velocity pressures) including their geographical distribution, characteristics, magnitude (in statistical terms), air densities, and in some cases the directional characteristics, if possible or necessary,

- the influence of localised features like: terrain roughness (i.e. wind profile and turbulence intensity), topography and shielding, and

- the susceptibility of various types of structures to wind action, in other words the capacity to generate certain magnitudes of wind pressures and forces as well as vibration while subjected to wind flow.

In the late 1950s, several of the national codes of practice which were introduced throughout the world were based on the Swiss building code (SIA 160 [46]). The information on pressure coefficients referred to the mean value and was based on early measurements which were carried out in mechanical (i.e. laminar flow) wind tunnels. The nominal forces were defined in combination with the gust wind speed estimated to be exceeded once in 50 years. 
Since then, more data have been obtained from measurements in simulated boundary layers and introduced into various design standards. Pioneering work in this respect started in 1950s by Martin Jensen (Denmark). His first results were published in English in 1965 (Jensen \& Franck [30]).

In the past 30-40 years a philosophy of adopting the mean wind speed has emerged due to its relevance and applicability to the dynamic design of structures. Some codes which implemented this philosophy then reverted to conversions to peak wind speeds following the Eurocode 1-4 [16].

\subsection{Formal AND INFORMAL DEVELOPMENT}

In the developed countries most, if not all, new structures have to comply with a minimum set of design specifications and/or regulations. In many cases the regulatory requirements are also applied retrospectively in that existing structures have to be modernised or upgraded in order to comply with the current safety and structural requirements.

The enforcement of these principles in developing countries is far more difficult, if not impossible. As a result, in many 'countries of the South' two mainstream types of construction markets and sectors coexist (i.e. the formal and informal). In South Africa, the best example of this situation is the housing sector in which, for various reasons, no standard requirements have historically been enforced in the rural areas. Furthermore, even within urban areas a sharp contrast is apparent between the relatively high standards of formal housing and dismally low standards of informal (often squatter) areas.

\section{Adoption of EUROCODE WIND LOADING PROCEDURES}

An implementation or adoption of any new engineering design stipulations introduces a formidable challenge to the developers of the standards and the design profession. This has been experienced in some of the countries (e.g. the UK, Australia and the USA), where processes of modernising the outdated codification took place in the past, and is currently applicable to the member countries of CEN (European Committee for Standardisation).

In this regard there is a major difference between the circumstances of Poland and South Africa. Poland, as an EU member state, has a compulsory obligation to adopt the new uniform standardisation requirements, within a stipulated time-frame. South African code developers, after a thorough investigation process which will be summarised below, decided on the voluntarily basis to adopt the Eurocode as a primary model document. In this respect, South Africa is one of the few countries outside the EU which adopted such an approach. Some other non-member European countries also adopted the Eurocode process or some of the provisions. 
The adoption processes which were undertaken in both countries, as well as the most important challenges in adopting the Eurocode wind loading procedures, will be highlighted.

\subsection{Poland}

\subsubsection{Historical perspective}

The first known wind loading stipulations for structures were included in a publication on statics of structures due to a renowned structural engineer Maksymilian Thullie, who stated that the basic wind speeds in Poland rarely exceed $30 \mathrm{~m} / \mathrm{s}$ and this value is adopted in the design of roofs (Żurański [51]). This statement reflected the widespread opinion, at that time, on the design wind speed in central Europe. Higher values were typically adopted in coastal areas or selected cities (e.g. Vienna at $40 \mathrm{~m} / \mathrm{s}$ ).

After World War I several countries, including Poland, regained their independence, but typically continued with former wind design specifications. Provisions from 1923 stipulated a minimum velocity pressure of $0.5 \mathrm{kPa}$ for structures sheltered by trees or other buildings and $1.0 \mathrm{kPa}$ for exposed structures, with a height of up to $12 \mathrm{~m}$. Following World War II, velocity pressure of $0.5 \mathrm{kPa}$ was stipulated for all structures in Zone I, up to the elevation of $10 \mathrm{~m}$. In the design standards from 1952 and 1954 three wind zones were stipulated, with the velocity pressures of $0.5,0.65$ and $1.0 \mathrm{kPa}$ respectively, and up to the height of $10 \mathrm{~m}$. Information was given regarding the relationships of the wind speed, pressure and site altitude above sea level as well as the magnitude of selected pressure and force coefficients.

From 1962 the Council of the Mutual Economic Aid (CMEA) recommended, and enforced in the Soviet block, the standard of the former USSR. This created inconsistencies in terms of the averaging time and also the magnitude of velocity pressure. Successive Polish Standards were introduced in 1964 (based on the above-mentioned USSR document) and in 1970 - with modifications to the extent of wind zones, introduction of a dynamic loading, according to the Barstein method (see Żurański, [51]) and more loading cases of roofs based on the Swiss code.

In the mid 1970s a committee was set up to develop a new wind loading code, with three overriding aims, namely to simplify the code, relate it to the relevant state-of-theart documentation from Denmark and Canada, and to maintain the current magnitude of wind speed in Zone 1 (enveloping most of the country). The development of the code was preceded by a process of introducing uniform wind speed recording instrumentation across the country. Due to the relatively short period of wind speed records, the Weibull probability distribution was used as a parent distribution over some threshold values in developing the relevant values of wind speed with a 50 -year return period (Żurański, [50]).

The following was achieved/introduced: 
- the wind speed basic averaging time of $10 \mathrm{~min}$, with its characteristic value determined statistically,

- this value was referred to a $10-\mathrm{m}$ elevation in a standard open terrain and with the mean return period of 50 years,

- the extent of the geographic zones was largely maintained (i.e. Zone I most of the country, Zone II coastal region, and Zone III mountainous region. (This was consistent with the previous and present zones, as shown in Figure 28),

- three terrain categories, together with the exposure factor,

- an empirical relationship reflecting changes of wind speed with elevation above sea level,

- a division into dynamically sensitive and insensitive structures (for the latter structures a factor of 1.8 was adopted to accommodate a conversion from a 10-min mean to a $10 \div 15 \mathrm{sec}$ peak velocity pressure and for small elements a factor of 2.2 to convert to $1 \div 3 \mathrm{sec}$ gust),

- a gust response factor according to Davenport [13] approach (similar to that in the Danish and Canadian codes), and

- a simplification of the code was achieved by introducing graphical representation of various relationships regarding pressure and force coefficients.

Following these changes, the 1977 version of the Polish standard [42] was considered as modern and on par with other international standards. The code was in use for more than 30 years, until it was formally replaced by the Eurocode on 31 March 2010.

\subsubsection{Implications and the National Annex}

The implications of introducing the new Eurocode stipulations can either be considered in terms of the changes in the relevant processes and parameters (e.g. design pressures or pressure coefficients) or related to the final outcome of the design process for various types of structures located in various circumstances. The initial consideration offers an overview of the situation and is summarised below. The latter investigation is out of the scope of the present paper.

The analysis of the implications of the new wind loading stipulations should take into account the following changes in relation to the old stipulations:

- an adoption of the instantaneous value of the wind pressure (and not the 10-min mean),

- the replacement of the gust response factor with the structural factor $\mathrm{c}_{\mathrm{s}} \mathrm{c}_{\mathrm{d}}$ (which combines the effects of non-simultaneous occurrence of peak wind pressure and vibrations of structures due to turbulence),

- the increase in the partial safety factor from 1.3 to 1.5 and,

- an increase in the characteristic values of wind speed (in National Annex).

The introduction of the new standard has a significant impact on the Polish design industry practice. The new stipulations include substantially more detail and require more configurations to be considered. Several aspects and processes have been changed 
e.g. the transition of the mean 10-min velocity pressure into the peak instantaneous value, the algorithm describing the vertical growth of boundary layer was modified from 'power' to 'logarithmic' law, and a new principal quantity of the intensity of turbulence was introduced.

Three out of five terrain categories correspond to those in the previous standard (Figure 26). The exposure factor considers not only the impact of the terrain category and elevation but also the intensity of turbulence. (This factor also enables to convert the 10-min mean velocity pressure to an instantaneous value.)

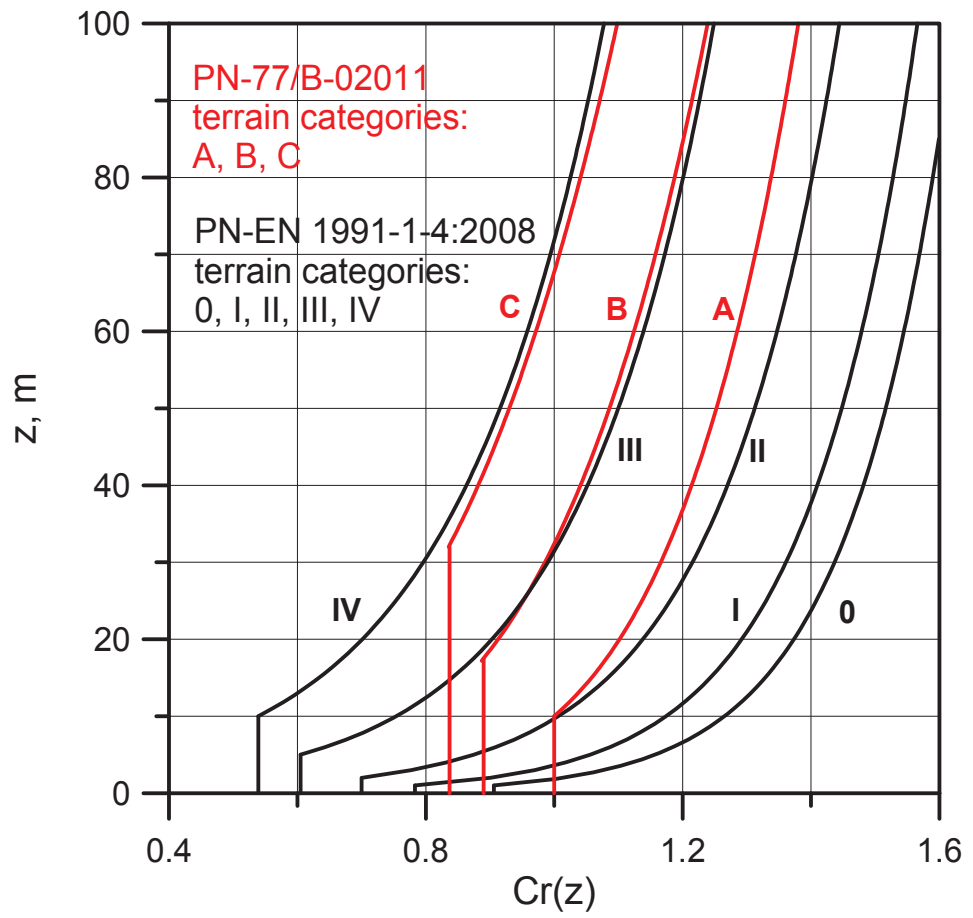

Fig. 26. Roughness coefficient according to the former Polish Standard PN-77/B-02011 and Eurocode 1 implemented in Poland as PN-EN 1991-1-4:2008.

More detailed information is provided regarding the external pressure coefficients and the development of internal pressures. Two procedures for calculating the structural factor as well as two approaches for calculating the response of dynamically sensitive structures to vortex excitation, are given.

Some of the pressure coefficients are questionable, especially those substantially smaller than in the latest Polish standard. This refers to due-pitch roofs with slopes between $0^{\circ}$ and $40^{\circ}$ (Figure 27). For example, for slopes of $20^{\circ}$ the values of $\mathrm{C}_{\mathrm{pe}, 10}$, area $\mathrm{H}$ according to Eurokod 1-4 [43] are three times smaller than the equivalent one in 
the Polish code. (Recently CEN permitted departures from the values of roof pressure coefficients given in the Eurocode 1-4 [16], but Poland has not chosen that option yet.)

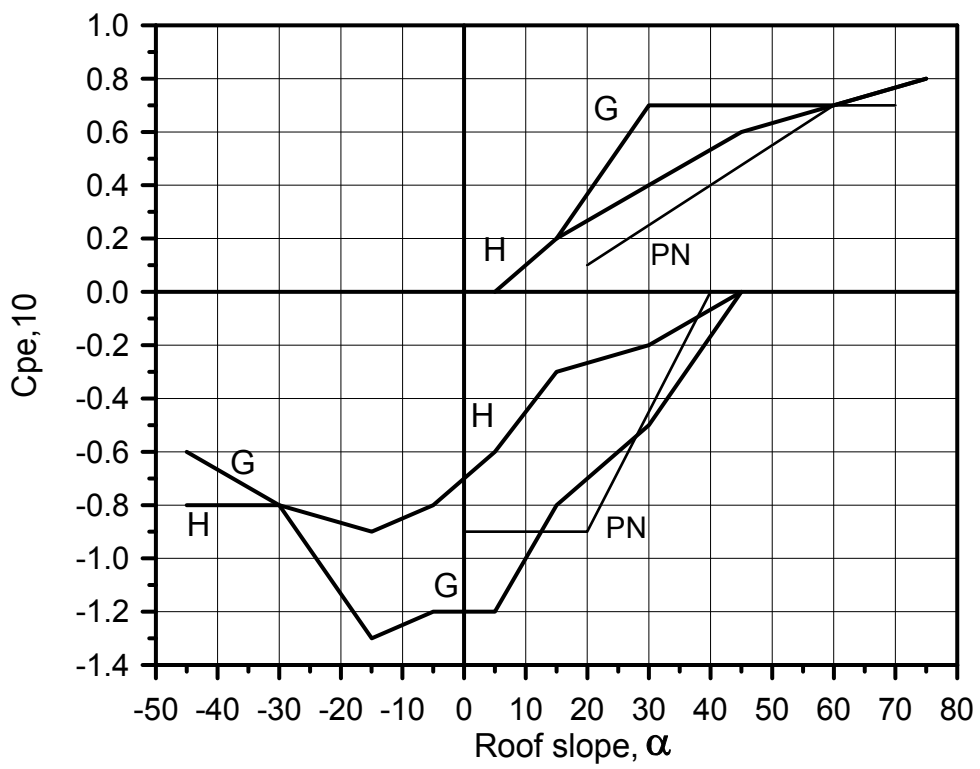

Fig. 27. External pressure coefficients for duopitch roofs according to Eurocode 1 (lines $G$ and $H$ ) and Polish Standard (lines PN) (Żurański and Gaczek, 2011).

In the Polish National Annex a set of new values of the free-stream dynamic pressures are given in terms of the elevation above sea level, directional factors, roughness and exposure factors. These are provided in terms of the power law formulation and can be used for the design of structures up to $500 \mathrm{~m}$. Nevertheless application of the Eurocode $[16,43]$ is limited to buildings with heights up to $200 \mathrm{~m}$ (the scope of the application in the latest Polish standard was not clearly defined). For buildings (and other structures) that fall outside the scope the most common method of evaluating wind actions is performing wind-tunnel tests, e.g. see Ćwik et. al. [12]. This method is also acceptable by Eurocode as a supplementary to code estimation procedures.

The magnitude of the basic wind speeds for the National Annex was derived from 40 years of records by using Gumbel-type extreme value analysis. In this analysis 12 directional sectors were considered.

Traditionally, the geographical area of Poland was divided into three zones of wind loading (1-3), as presented in Figure 28. The values of the basic wind speed and velocity pressure are presented in Tables 2 and 3. 
Table 2

Fundamental basic wind speed values included in the Polish National Annex to Eurocode 1 (PN-EN 1991-1-4:2008)

\begin{tabular}{|c|c|c|}
\hline \multirow{2}{*}{ Zone } & $\begin{array}{c}v_{b, o} \\
(\mathrm{~m} / \mathrm{s})\end{array}$ & $\begin{array}{c}v_{b, o} \\
(\mathrm{~m} / \mathrm{s})\end{array}$ \\
\cline { 2 - 3 } & $A \leq 300 \mathrm{~m}$ & $A>300 \mathrm{~m}$ \\
\hline 1 & 22 & $22 \cdot[1+0,0006(A-300)]$ \\
\hline 2 & 26 & 26 \\
\hline 3 & 22 & $22 \cdot[1+0,0006(A-300)]$ \\
\hline \multicolumn{2}{|l}{ NOTE: $A-$ Altitude above sea level, $\mathrm{m}$} \\
\hline
\end{tabular}

Table 3

Fundamental basic values of the wind velocity pressure according to Polish National Annex to Eurocode 1 (PN-EN 1991-1-4:2008)

\begin{tabular}{|c|c|c|}
\hline \multirow{2}{*}{ Zone } & $\begin{array}{c}q_{b, o} \\
\left(\mathrm{kN} / \mathrm{m}^{2}\right)\end{array}$ & $\begin{array}{c}q_{b, o} \\
\left(\mathrm{kN} / \mathrm{m}^{2}\right)\end{array}$ \\
\cline { 2 - 3 } & $A \leq 300 \mathrm{~m}$ & $A>300 \mathrm{~m}$ \\
\hline 1 & 0,30 & $0,30 \cdot[1+0,0006(A-300)]^{2}$ \\
\hline 2 & 0,42 & 0,42 \\
\hline 3 & 0,30 & $0,30 \cdot[1+0,0006(A-300)]^{2} \cdot\left[\frac{20000-A}{20000+A}\right]$ \\
\hline
\end{tabular}

In Zone 1, which envelops most of the territory of the country, with the basic 10-min mean wind speed, referred to $10 \mathrm{~m}$ above ground level in the open, standard terrain (category II) and 50-year return period is $22 \mathrm{~m} / \mathrm{s}$ (although until recently it was $20 \mathrm{~m} / \mathrm{s}$ ). The peak values, in terms of the $1-3 \mathrm{sec}$ gust wind speed, in Zone 1 are between $30 \mathrm{~m} / \mathrm{s}$ and $34 \mathrm{~m} / \mathrm{s}$. These values are determined by a conversion from 10-min mean wind speeds recorded in winter storms but also correspond to the wind speeds recorded in thunderstorms. Effectively, upon the introduction of the Eurocode, the values quoted above will increase up to $41 \mathrm{~m} / \mathrm{s}$ due to the increase in the characteristic value as well as the partial factor (if attributed to the wind speed only). This value is higher than the wind speed ever recorded within this zone.

The above changes will have significant implications on the design of structures, for example, in Zone 1, at an elevation of $10 \mathrm{~m}$, in open terrain category A, a 38\% (i.e. $[0,30 / 0,25] \cdot[1,5 / 1,3])$ increase in the loading can be expected.

The basic value of the wind speed in Zone 3 is the same as in Zone 1 but it is also stipulated in terms of the elevation above sea level. The same applies to Zone 1 in refer- 


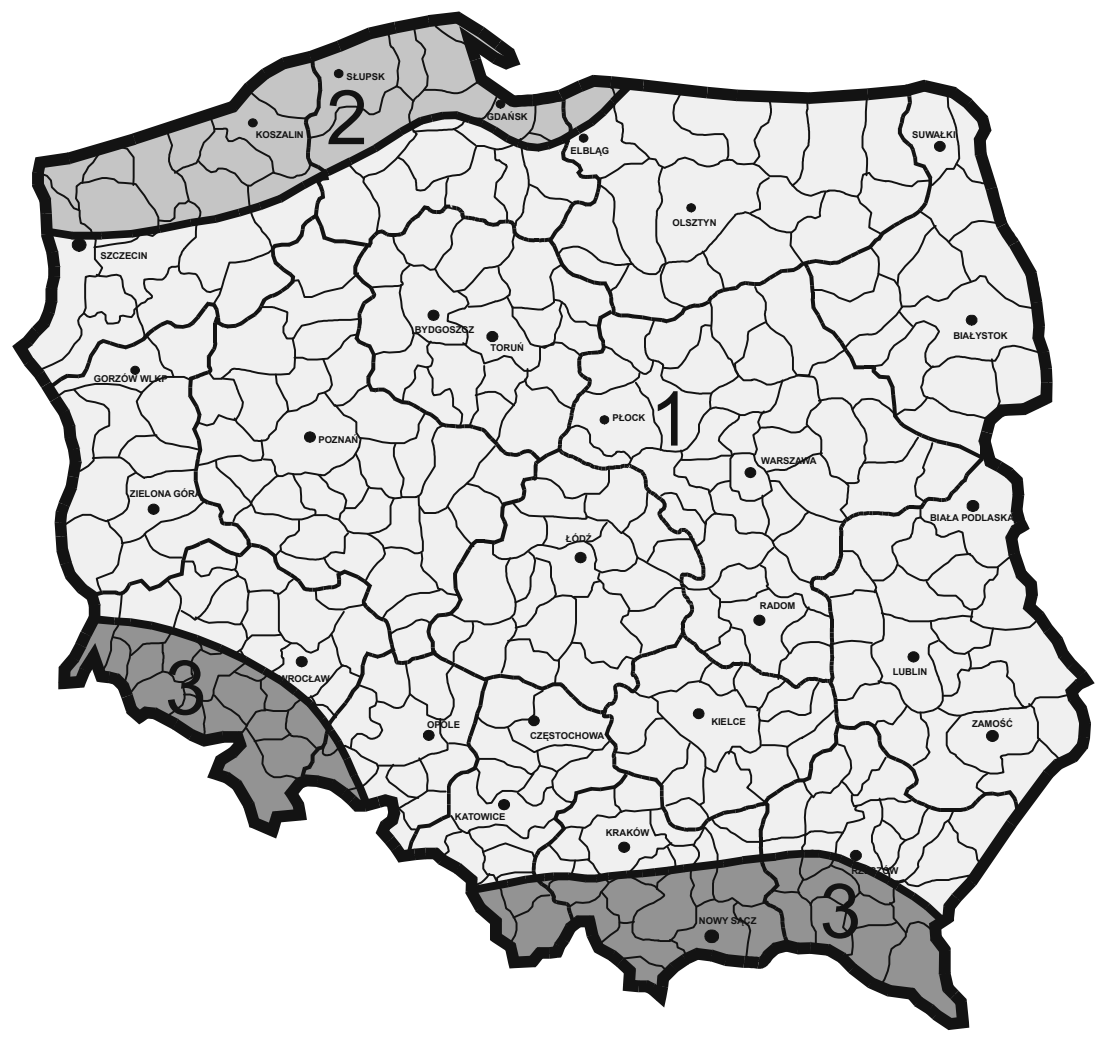

Fig. 28. Wind loading zones in Poland (in conjunction with Table 3 and 4) according to PN-EN 1991-1-4:2008

ence to the Świętokrzyskie Mountains, although no account was taken for the change in air density due to the very limited geographical extent of these mountains.

A graphical interpretation of the directional factor is presented in Figure 29. The factor is given in terms of 12 sectors of $30^{\circ}$ each. Sector 1 refers to true north i.e. azimuth $360^{\circ}\left(0^{\circ}\right) \pm 15^{\circ}$, and further division in a clockwise direction in a step of $30^{\circ}$. A value of $C_{\mathrm{dir}}=1,0$ is given:

- in Zone 1 for sectors 10 and 11,

- in Zone 2 for sectors 1, 2, 11 and 12, and

- in Zone 3 for sector from sector 7 to 11 .

In all other sectors the values of the directional factors are smaller: $0.7 \leq c_{\mathrm{dir}} \leq 0.9$. This implies that the loading can be substantially lower (up to 51\%) than the value corresponding to westerly winds.

The National Annex also provides algorithms to calculate the roughness and exposure factors, in terms of the power-law function (Table 4). This enables an easy integra- 
tion of the overall loading and can be used for structures higher than $200 \mathrm{~m}$, as limited in the Eurocode 1-4 [16]. The Eurocode stipulates a logarithmic profile applicable up to $200 \mathrm{~m}$ only.

A further departure of the Polish National Annex refers to the development length of the upwind fetch of terrain, affecting the adoption of terrain category. The principle was adopted in cases where the distance between the structure and the upwind extent of
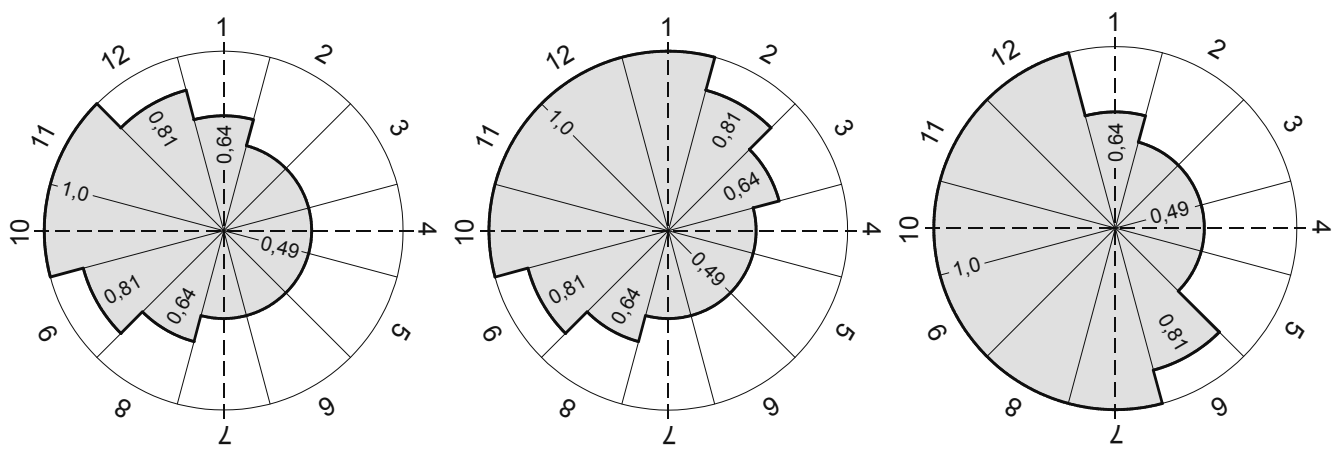

Fig. 29. Distribution of the square value of the directional factor for Zones 1-3

(Żurański and Gaczek, 2011).

Table 4

Roughness and exposure factors and heights $z_{\min }$ and $z_{\max }$, according to PN-EN 1991-1-4:2008

\begin{tabular}{|c|c|c|c|c|}
\hline Terrain category & $\mathrm{c}_{\mathrm{r}}(\mathrm{z})$ & $\mathrm{c}_{\mathrm{e}}(\mathrm{z})$ & $\mathrm{z}_{\min }, \mathrm{m}$ & $z_{\max }, m$ \\
\hline 0 & $1,3 \cdot\left(\frac{z}{10}\right)^{0,11}$ & $3,0 \cdot\left(\frac{z}{10}\right)^{0,17}$ & 1 & 200 \\
\hline I & $1,2 \cdot\left(\frac{z}{10}\right)^{0,13}$ & $2,8 \cdot\left(\frac{z}{10}\right)^{0,19}$ & 1 & 200 \\
\hline II & $1,0 \cdot\left(\frac{z}{10}\right)^{0,17}$ & $2,3 \cdot\left(\frac{z}{10}\right)^{0,24}$ & 2 & 300 \\
\hline III & $0,8 \cdot\left(\frac{z}{10}\right)^{0,19}$ & $1,9 \cdot\left(\frac{z}{10}\right)^{0,26}$ & 5 & 400 \\
\hline IV & $0,6 \cdot\left(\frac{z}{10}\right)^{0,24}$ & $1,5 \cdot\left(\frac{z}{10}\right)^{0,29}$ & 10 & 500 \\
\hline
\end{tabular}


the terrain category, in which it resides, is larger than $30 \mathrm{~h}$ (where $\mathrm{h}$ is the height of the structure). In such cases, this terrain category can be adopted.

Research has shown that this principle is sound and acceptable (Żurański [52]). The corresponding stipulations in Eurocode 1-4 [16] are substantially more conservative and would prevent the use of the city built-up terrain category.

The terrain categories should be considered in terms of the directional sectors discussed above.

Polish National Annex recommends the use of Procedure 1 for the determination of the structural factor and also Approach 2 in respect of calculation of the amplitudes of cross wind vibration of slender tall structures due to vortex excitation. An analysis of failure of a $100-\mathrm{m}$ tall steel chimney indicated that Approach 2 provides a better assessment of the risk due to excessive deflections at the top of the structure subject to cross wind excitation (Kawecki \& Żurański [32]).

The Eurocode 1-4 [16] wind loading stipulations are significantly different from those included in the latest Polish version of the loading standard. This situation requires a substantive information and educational effort to propagate the Eurocode within the design industry. This is the aim of general publications (e.g. Żurański [57]) or a commentary document (Żurański \& Gaczek [58]).

The growing number of wind-related catastrophes prompted the development of several related publications (Gaczek \& Żurański [18], Żurański \& Gaczek [53], Żurański et al. [55]) and a guide on the protection of buildings against strong wind action (Żurański et al. [59]). Due to the enormous magnitude of wind speeds in tornadoes (Chmielewski et al. [6]) it is not possible to design the structures to withstand such wind speeds. However, several design rules can be identified and propagated to reduce the extent of the damage.

\subsection{South Africa}

\subsubsection{Background and the process}

It is important to note that the South African design standards reflect the consensus of the profession on the acceptable design practice for structural safety and economic performance of structures, as opposed to prescriptions of the regulatory authorities.

The 1989 version of the standard (SABS 10160-1989 [44]) was developed in the mid-1980s. Its wind loading stipulations are based on the old British code (CP3 [8]). In 1998 the South African National Conference on Loading took place, which provided a national discussion forum and initiated a process of modernising and re-aligning with modern international codification.

An overview and comparative assessment of wind loading stipulations was presented (Goliger et al. [20]), which showed a need for a significant transformation and modernising of those stipulations. The idea of developing an original (i.e. unique) set of wind loading stipulations was discarded and it was decided that efforts should be 
directed at analysis of selected international standards and identification of those most relevant to the South African situation and investigating ways of optimising and improving these documents for further adoption (Goliger et al. [21, 24]).

A reasonable assumption was made that, for this process, the loading standards of South Africa's major trading partners - i.e. Europe (at that stage ENV version) and the USA (ASCE 7-98 [2]) - should be considered. The Australian standard (AS 1170.2 [1]) was also identified as being of interest, in view of its climatic similarities as well as technical and economical synergies with South Africa. (At the time when the comparative analysis of international codes was taking place, wind loading stipulations of the ISO code were not in place, although an international effort to revive the work of the TC98/SC3/WG2 committee was gaining momentum.)

The analysis has shown that, although all abovementioned wind loading standards encapsulated modern approaches and information, each of them also posed several challenges for adoption in South Africa. The most suitable document was found to be the Australian code (AS 1170.2 [1]). However, in 2002, information reached the South African loading committee which indicated that preparatory work on a new version of the Australian wind loading standard was in progress. In view of this development, the merits of adopting an 'outdated' version of a document from abroad became questionable.

At the same time, a close relationship was forged between the Eurocode committee and the South African loading committee. This included several visits, discussions and participation in Eurocode committee meetings. It also became evident that the United Europe embraces the role of a strong economic power block within the commercial construction environment of the Europe-Africa region.

In view of the above developments, the loading committee decided to undertake a re-analysis of the most recent wind loading version of the Eurocode, and the implications of its adoption for South Africa. The latest copy of the draft code (from December 2003) was obtained from the Eurocode committee. A brief overview of the code indicated this to be an excellent and state-of-the-art document, at a fairly advanced stage of finalisation. It also became apparent that adoption of the code in South Africa would markedly increase the amount of design work in comparison with the current SABS 10160-1989 document.

Furthermore, a review of the basic principles of the Eurocode indicated a problem of adopting the definition of the 'characteristic wind speed' in terms of the 10-min mean, as opposed to the 3-sec gust wind speed, used in the SABS 10160-1989.

\subsubsection{Major challenges}

The set of new wind loading stipulations (SANS 10160-3:2011 [45]), based on the Eurocode procedures introduced significant changes to the design processes of the SABS 10160-1989. The most relevant and radical issues/changes are highlighted in the current paper. These refer to the: 
- adoption of the 10-min averaging time, basic wind speed

- new procedure regarding the correlation of the external pressures,

- adoption of a new set of wind speed profiles, and

- the likely increase in the magnitude of the design loads.

A more detailed discussion in this regard has been presented in Goliger et al. [25].

\section{Wind speed averaging time}

The most critical characteristic of strong winds, that directly affects the extent of damage, is the magnitude of wind speed. The analysis by Milford [38] formed the basis for the maps of Regional Basic Wind Speed (in terms of 3-sec gust) and maximum mean hourly wind speed, which form the wind loading specifications of the South African standard (SABS 10160-1989) and are included in Figure 30a and 30b. These maps were based on extreme-value analysis of long-term records from only 14 reliable and long-term (then) South African Weather Bureau recording stations.
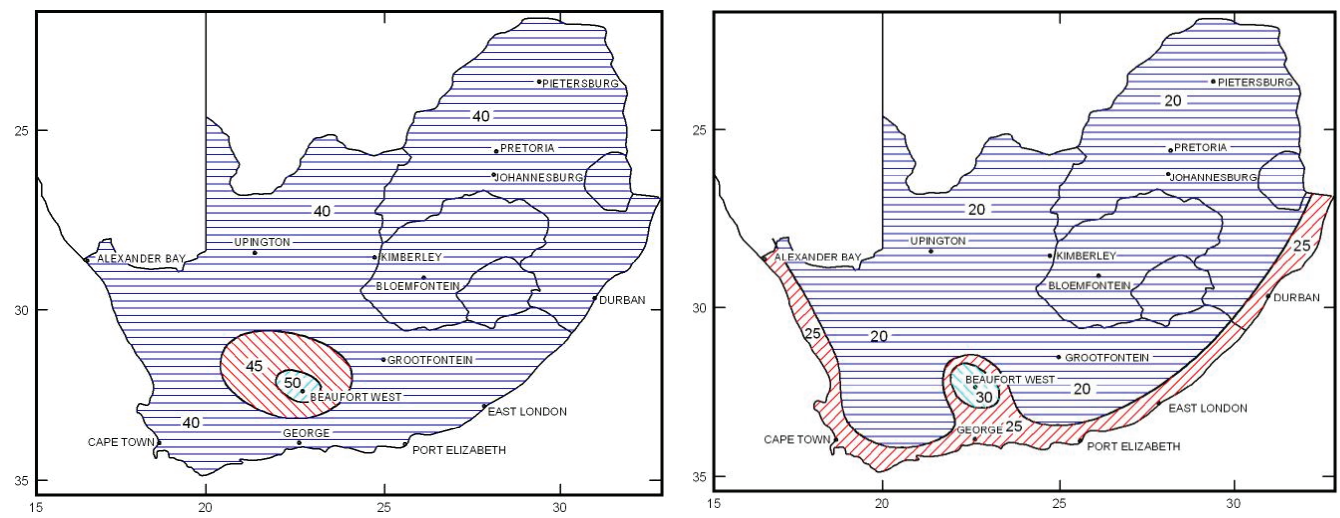

Fig. 30. Isopleths of maxima a) 3-sec gust wind speed, b) mean hourly wind speed.

Large differences in the gust factor between the coastal and inland terrain, which are shown in Figures 30a and 30b, reflect the complexity of the South African wind climate, as indicated elsewhere in this paper. The discrepancy is summarised in Table 5, from which it can be seen that the gust factor ranges between 1.6 and 2.0. This matter forms one of the basic problems in adopting the wind loading design procedures based on the 10-min mean wind speed, as in the proposed Eurocode specifications. A more detailed discussion in this regard is included in Goliger [23].

The data presented in Table 5 demonstrate the difficulty of climates dominated by convective events to be represented by large averaging periods and this issue has only been recognised in the proposed ISO code. 
Table 5

Comparison of wind speeds and gust factors

\begin{tabular}{|c|c|c|c|}
\hline Area & $\begin{array}{c}\text { Regional basic wind speed, } \\
\text { 3-sec gust (m/s) }\end{array}$ & $\begin{array}{c}\text { Maximum mean hourly } \\
\text { wind speed }(\mathrm{m} / \mathrm{s})\end{array}$ & $\begin{array}{c}\text { Wind gust } \\
\text { factor }\end{array}$ \\
\hline Coast & 40 & 25 & 1.6 \\
\hline Inland & 40 & 20 & 2.0 \\
\hline
\end{tabular}

Unfortunately, the stipulation of the Eurocode regarding the definition of the averaging time is non-negotiable and the 10-min averaging time has, therefore, been adopted in the proposed South African code. This necessitated an introduction of a map of the fundamental basic wind speeds to be based (depending on the geographical area) on the actual and 'equivalent' values of 10 -min wind speeds.

\section{Accounting for correlation of pressures}

A structure exposed to wind will experience a steady wind load (due to the mean wind speed component of the flow) and fluctuating loads about the mean. These fluctuating loads will vary from low frequency forces caused by large gusts (capable of enveloping an entire structure), to high frequency and relatively disorganised small gusts affecting localised areas of the structure.

SABS 10160-1989 wind loading stipulations were based on an approach (shared, historically, with several international design standards as well as the CP3) in which the maximum load can be approximated by an equivalent gust profile enveloping the entire structure at the same instance of time as presented in Figure 31. The shortcoming of this approximation is that it ignores the effect of the size of a structure, i.e. the fact that the larger the loaded area, the smaller the correlation of gusts becomes. To compensate for this, the code introduces a 'division' into classes of structures with different gust wind speed profiles (averaging periods). This is reflected in Figure 31 from which it can be seen that for the design of smaller building, a higher magnitude gust profile will be used. The approach of the Eurocode, which was incorporated in SANS 10160-3:2011, is more logical and transparent. Being based on updated international loading information it specifies more elaborate/detailed loading zones. Furthermore, to accommodate the correlation of pressures, all pressure coefficients given in the code are given in terms of two values for loaded areas of $1 \mathrm{~m}^{2}$ and $10 \mathrm{~m}^{2}$ respectively, which could be interpolated for areas in between. The differences in pressures between small and large areas are of the order of $50 \%$ and even more, as compared to the range of $4 \%-8 \%$ differences for different building classes of the old procedures.

\section{Boundary-layer profiles}

There are significant differences in the description of terrain categories adopted in the SABS 10160-1989 and EN 1991-1-4. SABS 10160-1989 stipulated four terrain 


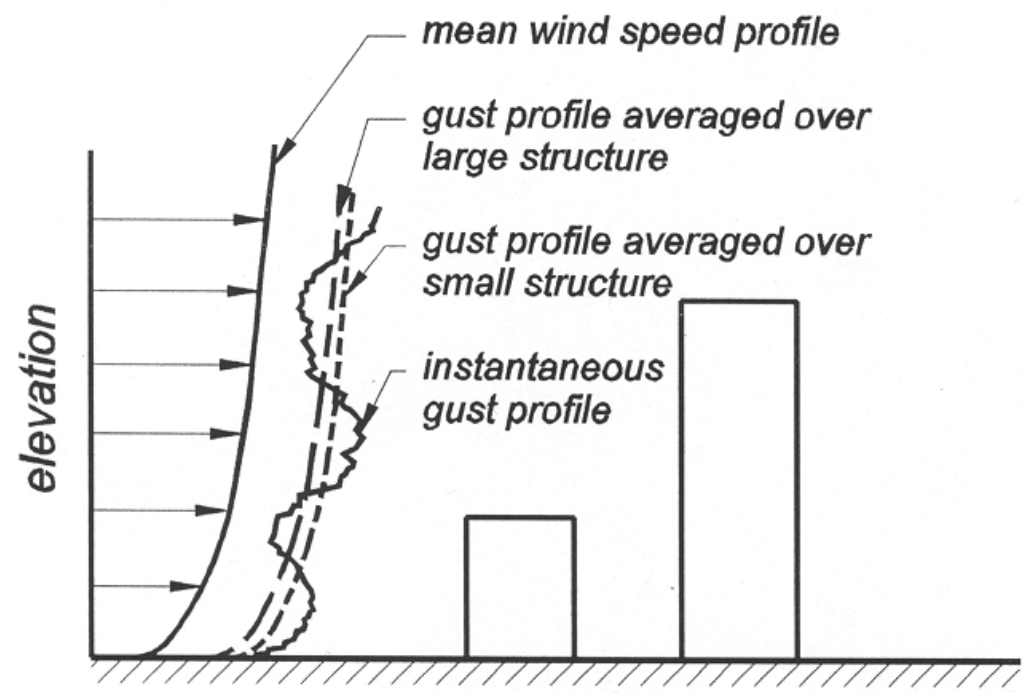

Fig. 31. Illustration of peak gust acting on structure.

categories (1-) in terms of typical descriptions of land cover and the character of the built environment. The division given in the Eurocode into five terrain categories (from 0 to IV), appears to be less ambiguous in a sense that is defined in terms of the mutual relationship between the average heights of obstacles and the relative amount of open space between them.

The Eurocode does not stipulate a fully developed city terrain profile. This is in line with an approach (and argument) implemented in some of the recent European codes (e.g. BS 6399 [5]). In this argument, a development of the 'city terrain' profile is unrealistic, as it would require several kilometres of development length, which do not exist in most cities of the world.

In Figure 32, profiles obtained for terrain category 2 (SABS 10160-1989) and category II (EN) are compared. The SABS profile was based on $40 \mathrm{~m} / \mathrm{s}$ regional basic wind speed and the EN profile on $28 \mathrm{~m} / \mathrm{s} 10$-min basic wind velocity. By implication, the above descriptions (i.e. terrain categories) should match, as in both standards they represent the terrain on which the regional basic wind speeds are based. This is also consistent with the stipulation of the World Meteorological Organisation regarding the full-scale measurement of regional wind speeds.

Note that in each graph the SABS profiles are represented by three lines which correspond to 3, 5 and 10-sec averaging periods - i.e. A, B and C classes of structures. This stipulation accommodates the correlation of flow, and is in line with the philosophy of the old CP3. It can be seen in Figure 32 that a large discrepancy is evident and that the EN profile is more conservative. 


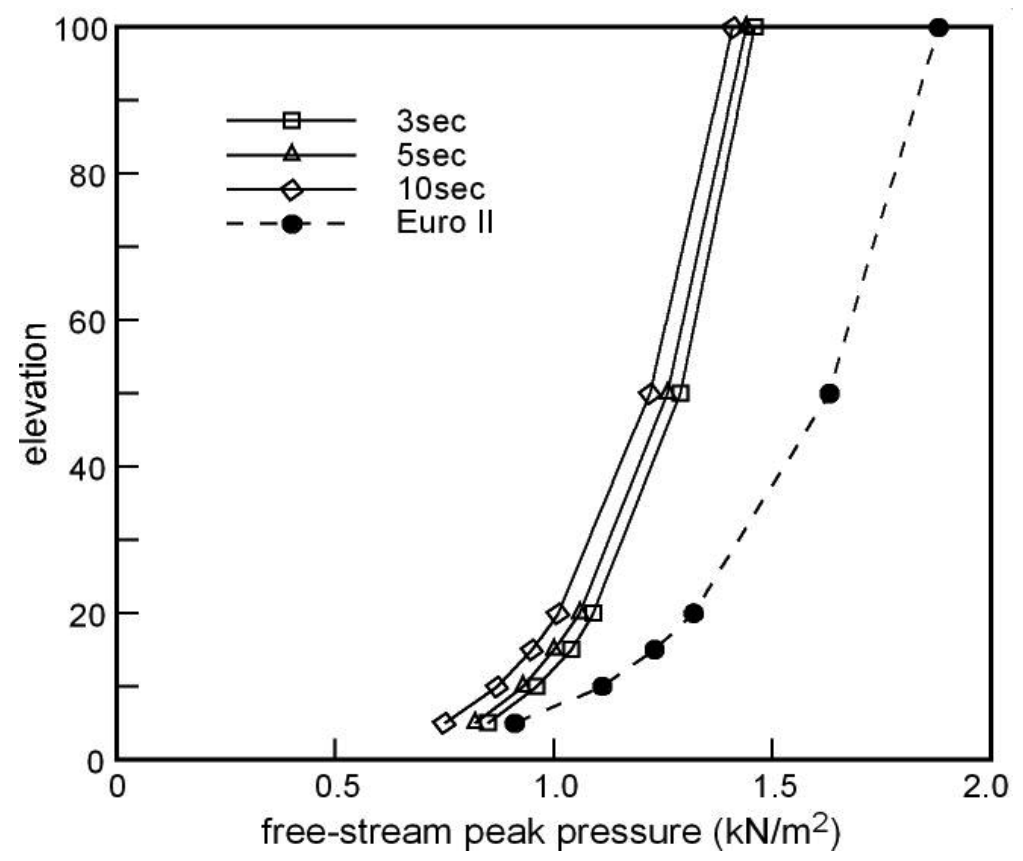

Fig. 32. Comparison of SABS (category 2) and Eurocode 1 (category II) profiles.

\section{Initial comparisons of loading}

In view of the differences between the principles and stipulations of various national codes across the world, it is very difficult, if not impossible, to compare individual components of the design chain in isolation, and the only 'fair' way to compare them is at a level of the resulting (unfactored) loads.

Keeping in mind the level of discrepancies between the free-stream wind speed and pressure profiles, results of a set of comparative calculations are presented below, regarding typical low-rise and medium-rise buildings, according to SABS 10160-1989 and EN 1991-1-4. This was provided in order to demonstrate and sensitise the designer to a possible range of differences between both design standards and to set the scene for further development of the South African standard.

A structure of a typical large warehouse, located in a coastal area, was assumed, as shown in Figure 33. Three roof slopes, $\alpha=5^{\circ}, 15^{\circ}$ and $30^{\circ}$, were considered, together with terrain categories:

- 1 (SABS 10160-1989) corresponding to 0 (EN) as being the 'smoothest',

- 2 (SABS 10160-1989) corresponding to II (EN) by implication of the reference terrain category, and

- 4 (SABS 10160-1989) corresponding to IV (EN) by being the 'roughest'. 


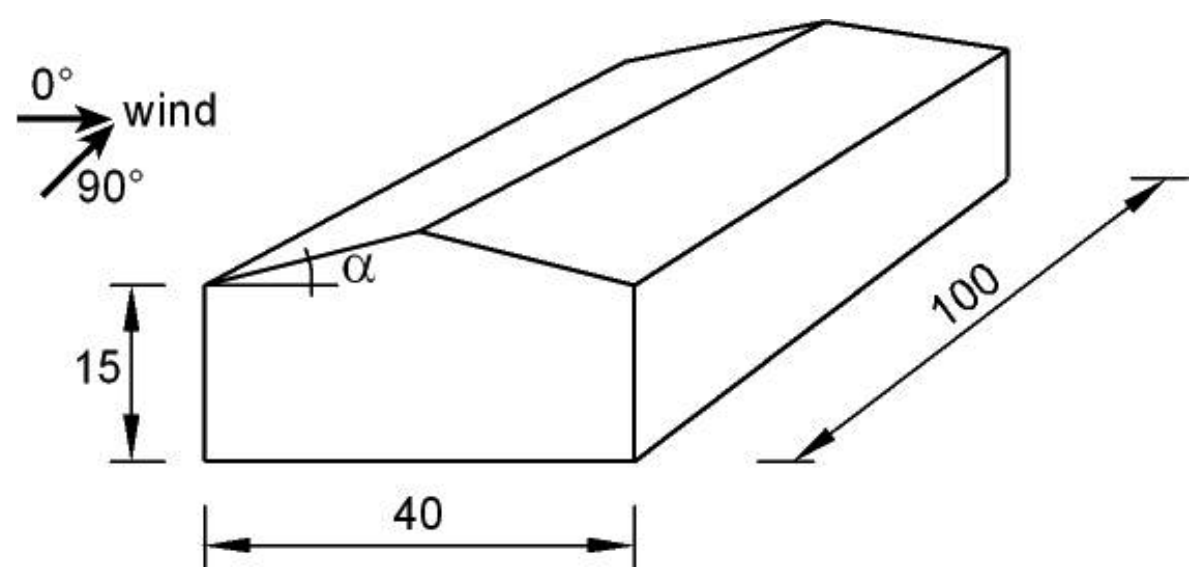

Figure 33. Geometry of the building.

Selected results of comparative calculations are presented in Figures 34a and 34b, in a form similar to regression analysis, which is often used for comparisons of two independent sets of corresponding data.

The data are plotted in a way where a specific load obtained for EN is plotted along the horizontal axis, and the load corresponding to the SANS code along the vertical axis. Each load is then represented by a single data point. The diagonal line at $45^{\circ}$ (regression line of unity) represents the situation where loads derived from both procedures are the same. A point below the regression line reflects the loads stipulated by the Eurocode procedure to be higher.

Figure 34a refers to local negative pressures over a tributary area of $5 \mathrm{~m}^{2}$, and Figure $34 \mathrm{~b}$ to the resultant uplift force of the entire roof. It can be seen that, apart from a few isolated situations, in both cases the loads that were derived from EN 1991 are significantly larger, especially for the localised areas. Calculations presented in Ćwik et al. [11] confirm the general conclusion that the wind loads evaluated according to the EN are larger in comparison to those evaluated according to SABS 10160-1989.

The large discrepancy apparent in Figure 34 results from a combination of differences in:

- the magnitude of free-stream dynamic pressure,

- the magnitude of pressure coefficients stipulated in both codes,

- geometrical extent/definitions of loading zones, and

- the disparities in application procedures - i.e. the way in which the pressures/loads are referenced or combined.

A more detailed description of differences and their influence on wind loads has been presented in Ćwik et al. $[9,10]$. 
a)

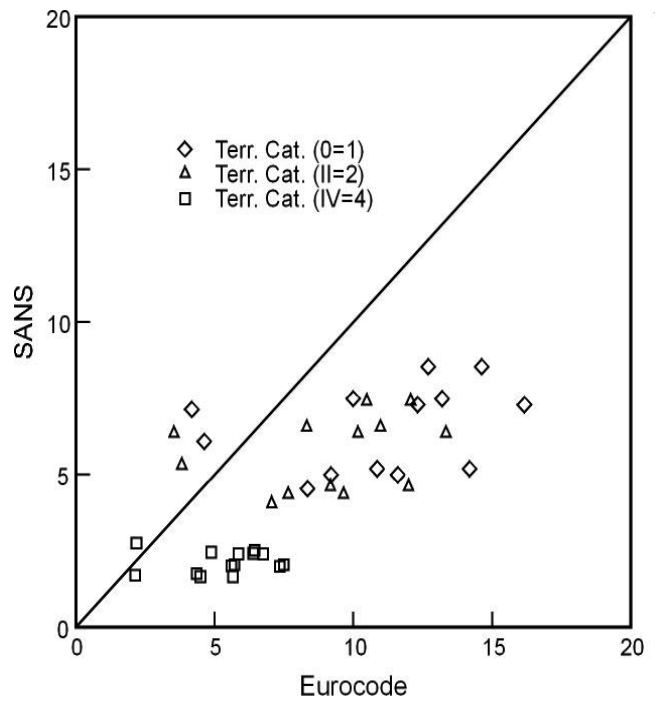

b)

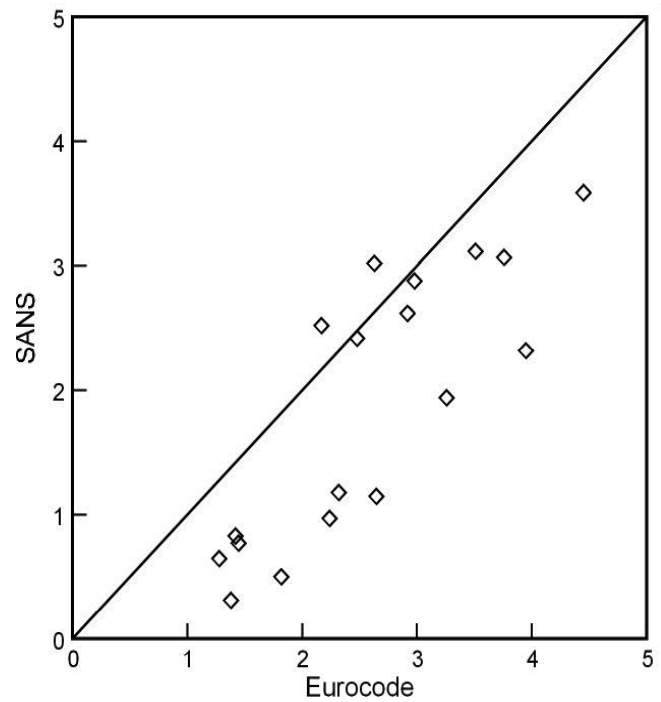

Fig. 34. Comparison of pressure values: a) local negative roof pressures; b) roof uplift.

\section{Summary and CONCLUSIONS}

This paper presents a comparative review of wind climatic conditions of Poland and South Africa, the wind-related damage to the built environment as well as the implications of introducing the new wind loading structural design specifications in both countries. A range of related issues has been discussed and several differences and similarities were identified.

The climate of South Africa is complex and creates a formidable problem in developing the relevant full-scale wind speed statistics, which form a critical input to wind loading codification. Poland is characterised by a relatively uniform meteorological conditions, but longer term climatic changes take place, as demonstrated by the increase in the occurrence of high intensity winds.

The regulatory notions for implementing the Eurocode wind loading principles and procedures in both countries differ substantially. Poland being a member state of the European Union is compelled to adopt the new set of design standards, while South Africa decided on a voluntarily adoption, following a comprehensive investigation process. The Eurocode stipulations are not readily applicable to both countries and a substantial amount of effort in this respect was undertaken by the authors of this paper. 


\section{AcKnowledgments}

The idea for the comparative research, presented in the current paper, was generated as a result of several technical interactions involving co-authors from both countries. These interactions, which also enabled the development of the paper, would have not been possible without the bilateral research sponsorship of the Polish Ministry of Science and Higher Education and the South African National Research Foundation (NRF).

\section{REFERENCES}

1. AS 1170.2, Australian Standard: SAA Loading code, Part 2: Wind loads. Standards Australia, 1989.

2. ASCE 7-98, ASCE Standard: Minimum design loads for buildings and other structures. American Society of Civil Engineers, 1998.

3. G. BebŁot, I. HoŁda, K. Rorbek, Tornado in the Częstochowa region on July 20, 2007. In: Ekstrema pogodowe Polsce (Weather extremes in Poland), M. Maciejewski, M.S. Ostojski (ed.), IMGW, Warszawa, 2007 [in Polish].

4. G. BERZ, The increasing significance of windstorms and the IDNDR, Journal of Wind Engineering and Industrial Aerodynamics, Vol. 41-44, 23-25, 1992.

5. BS 6399: Part 2, British Standard: Part 2, Code of practice for wind loads, BSI, 1997.

6. T. Chmielewski, H. NowaK, K. WALKowiak, Tornado in Opole province-effects, wind speed estimation, damage classification and reconstruction. Inżynieria i Budownictwo, 10, 526-529, 2010 [in Polish].

7. N.J. Соок, The performance of buildings in the United Kingdom, Proceedings of the Conference on Design Against Wind Induced Failure, Bristol, January, 1984.

8. CP3: Chapter V: Part 2, Code of basic data for the design of buildings, BSI, 1952.

9. M. Ć WiK, M. Giżejowski, A. Goliger, Wind loadings of structures - A review of wind characteristics, wind-tunnel testing, in-situ measurements, computer modelling and code estimation procedures, Proceedings of The XV International Seminar of IASS Polish Chapter: Lightweight Structures in Civil Engineering - Contemporary Problems (ed. J. Obrębski), Micro-Publisher-Consultant-Project, Warszawa, 45-63, 2009.

10. M. ĆWIK, M. Giżejowski, A. Goliger, Comparison of wind actions on buildings according to Polish and South-African codes. Part 1: Basis for codification procedures, Zeszyty Naukowe Politechniki Rzeszowskiej, Budownictwo i Inżynieria Środowiska, z. 59 (1/12/I), Nr 283, Oficyna Wydawnicza Politechniki Rzeszowskiej, Rzeszów, 35-54, 2012 [in Polish].

11. M. ĆWIK, M. GiżeJowski, A. Goliger, Comparison of wind actions on buildings according to Polish and South-African codes. Part 2: Illustrative, Zeszyty Naukowe Politechniki Rzeszowskiej, Budownictwo i Inżynieria Środowiska, z. 59 (1/12/I), Nr 283, Oficyna Wydawnicza Politechniki Rzeszowskiej, Rzeszów, 55-70, 2012 [in Polish].

12. M. Ćwik, M. GiżeJowski, A. Goliger, M. Sitek, Wind pressure loading for tall buildings. A case study of Warsaw Trade Tower, Proceedings of The XVIII International Seminar of IASS Polish Chapter: Lightweight Structures in Civil Engineering - Contemporary Problems (eds. J. Obrębski, W. Przybyło), Micro-Publisher-Consultant-Project, Warszawa, 78-85, 2012.

13. A.G. Davenport, Gust Loading Factors, Journal of Structural Division, ASCE, v.93, No ST3, 1967.

14. A.G. DAVENPORT, The role of wind engineering in the reduction of natural disasters, Special Paper, Proceedings of the $9^{\text {th }}$ International Conference on Wind Engineering, Wiley Eastern Limited, New Delhi, January, 1995.

15. N. Dotzeк, An updated estimate of tornado occurrence in Europe, Proceedings of the 2nd European Conference on Severe Storms, Prague, August, 2002. 
16. Eurocode 1-4, EN 1991-1-4, Actions on structures, Part 1-4 General actions - Wind actions. European Committee for Standardisation (CEN), Brussels, 2005.

17. A.H. Fink, T. Brücher, V. Ermert, A. Krüger, J.G. Pinto, The European storm Kyrill in January 2007: synoptic evolution, meteorological impacts and some considerations with respect to climate change, Nat. Hazards Earth Syst. Sci., 9, 405-423, 2009.

18. M. GacZeK, J.A. ŻuraŃSki, Strong wind damage to buildings. Inżynier Budownictwa, part $1 \mathrm{nr} 9$ (54)/ 2008 pp. 52-57, part 2 nr 10 (55) / 2008, 76-80 [in Polish].

19. A.M. Goliger, R.V. Milford, F. Adam, M. Edwards, Inkanyamba - tornadoes in South Africa, Joint publication of the CSIR and the SA Weather Bureau, Dept. of Environmental Affairs and Tourism, Pretoria, South Africa, 1997.

20. A.M. Goliger, H-J. Niemann, R.V. Milford, Assessment of wind-load specifications of the SABS 0160-1989, Proceedings of South African National Conference on Loading. SAICE, Johannesburg, September, 1998.

21. A.M. Goliger, R.V. Milford, J. Mahachi, South African wind loadings: where to go, A. Zingoni (Ed) Proceedings of International Conference on Structural Engineering, Mechanics and Computation, University of Cape Town, Cape Town, April, 1305-1312, 2001.

22. A.M. Goliger, J.V. Retief, Identification of zones of strong wind events in South Africa, Journal of Wind Engineering and Industrial Aerodynamics, No 90, 1227-1235, 2002.

23. A.M. Goliger, South African wind loading specifications: the Euro way?, J. Naprsteck \& C. Fischer (Ed) $4^{\text {th }}$ European \& African Conference on Wind Engineering, Prague, July, 2005.

24. A.M. Goliger, J.V. Retief, P.E. Dunaiski, Review of codification of wind-loading for structural design, Chapter 3-1 in J.V. Retief, P.E. Dunaiski (Editors). Background to SANS 10160. ISBN 978-1-92033810-7, SUN MeDIA, Stellenbosch, 2009.

25. A.M. Goliger, J.V. Retief, P.E. Dunaiski, A.C. Kruger, Revised wind-loading design procedures for SANS 10160, Chapter 3-2 in J.V. Retief, P.E. Dunaiski (Editors). Background to SANS 10160. ISBN 978-1-920338-10-7, SUN MeDIA, Stellenbosch, 2009.

26. L. Gomes, B.J. VickerY, Extreme wind speeds in mixed climates, Journal of Wind Engineering and Industrial Aerodynamics, Vol. 2, 331-344, 1978.

27. D.J. Greenwood, D.J. Hatheway, Assessing Opal's impact, Civil Engineering, Vol. 66, No. 1, January, 40-43, 1996.

28. GUNB, Building Catastrophes in 2005 and survey of catastrophes in 1995-2005, Główny Urząd Nadzoru Budowlanego, Departament Prawno-Organizacyjny, Warszawa, January 2006 [in Polish].

29. GUNB, Building Catastrophes. Yearly issues of surveys from 2006 to 2011, Główny Urząd Nadzoru Budowlanego, Departament Prawno-Organizacyjny, Warszawa, 2007-2012 [in Polish].

30. M. Jensen, N. Franck, Model-scale tests in turbulent wind. Part II, Wind Loads on Buildings. The Danish Technical Press, Copenhagen, 1965.

31. M. Kasperski, Specification and codification of Design Wind Loads, Habilitation thesis. RuhrUniversitat Bochum, 1999.

32. J. Kawecki, J.A. Żurański, Crosswind vibrations of steel chimneys - A new case history, Journal of Wind Engineering and Industrial Aerodynamics 95, 1166-1175, 2007.

33. A.C. Kruger, Wind climatology and statistics of South Africa relevant to the design of the Built Environment, $\mathrm{PhD}$ research dissertation at Stellenbosch University, South Africa, 2010.

34. A.Lisowski, Effects of the selected natural hazards and their perception in Poland. Warsaw University, Department of Geography and Regional Study, Warszawa, 1993 [in Polish].

35. H. Lorenc, Structure and energy resources of wind in Poland. Instytut Meteorologii i Gospodarki Wodnej, Materiały Badawcze, Seria: Meteorologia - 25, Warszawa, 1996 [in Polish].

36. LPC, Loss Prevention Council, http://www.lpc.co.uk, 2000.

37. J.R. McDonald, A methodology for tornado hazard probability assessment, Institute for Disaster Research, Texas Tech University, prepared for US Nuclear Regulatory Commission, NUREG/CR3058, 1983. 
38. R.V. Mitford, Annual maximum wind speeds for South Africa, The Civil Engineer in South Africa, Vol. 29, Issue 1, January, 1987, pp. 15-19, 1987.

39. Munich Re, Windstorm - new loss dimension of natural hazard, Munich Reinsurance Company, D-800 München 40, Germany, 1990.

40. Munich Re, Natural Hazards Assessment Network, Country Profile: Poland and South Africa, 2006, 2009.

41. Project R04 001 02: Assessment of the orographic and climatic influences on wind load on building structures in Poland, Instytut Techniki Budowlanej, Warszawa, 2010 [in Polish].

42. PN-B-02011:1977, Loads in static calculations. Wind loads. [in Polish].

43. PN-EN 1991-1-4:2008 Eurocode 1: Actions on structures - Part 1-4: General actions - Wind actions [in Polish].

44. SABS 0160-1989 (as amended 1990, 1991 \& 1993), South African standard code of practice for the general procedures and loadings to be adopted in the design of buildings, The South African Bureau of Standards, reprint 1994.

45. SANS 10160-3:2011, South African national standard. Basis of structural design and actions for buildings and industrial structures, The South African Bureau of Standards, 2011.

46. SIA 160, Normen für die Belastungsannahmen, die Inbetriebnahme und die Überwachung der Bauten, Schweizerischer Ingenieur-und Architekten Verein, Technische Normen Nr 160, 1956.

47. P.R. Sparks, G.T. Reid, W.D. Reid, S. Welsh, N. Welsh, Wind conditions in hurricane Hugo by measurement, inference and experience, Journal of Wind Engineering and Industrial Aerodynamics, Vol. 41-44, 55-56, 1992.

48. K. Stansfield, Global warming: issues for engineers, The Structural Engineer, Vol. 79, No. 14, 17 July, 2001.

49. G.R. Walker, G.F. Reardon, E.D. Jancaukas, Proceedings of the $7^{\text {th }}$ International Conference on Wind Engineering, Aachen, West Germany, Part 1, 139-148, July, 1987.

50. J.A. ŻuRAŃSKI, An analysis of the characteristic wind speeds in Poland. XXIV Scientific Conference of KILiW PAN and KN PZITB, Krynica, 1978 [in Polish].

51. J.A. Żurański, 100 years of some wind loading provisions in Central and Eastern Europe, Journal of Wind Engineering and Industrial Aerodynamics 91, 1873-1889, 2003.

52. J.A. ŻURAŃSKI, Effects of the climatic and topographic conditions on wind loads on building structures, Instytut Techniki Budowlanej, Dissertaions, Warszawa, 2005 [in Polish].

53. J.A. Żurański, M. GaczeK, Strong wind actions on buildings, X Scientific and Technical Conference on Building Expertises. Miedzeszyn, 22-24 April 2008 r., Proceedings, ITB, Warszawa, 2008 [in Polish].

54. J.A. ŻuRański, J. Szer, Tornado in Łódź province on 15 August 2008. Its genesis, run and effects, XII Polish Scientific and Technical Conference „Building Physics in the Theory and Practice”, Słok, 2009 [in Polish].

55. J.A. ŻurańSKi, M. GaCZeK, S. FIsZer, Catastrophic wind actions on buildings in Poland, XXIV Scientific and Technical Conference on Building Failures, Szczecin-Międzyzdroje, 2009 [in Polish].

56. J.A. ŻuRański, M. GACZeK, S. Fiszer, Character and occurrence of catastrophic winds in Poland, 55 Scientific Conference of KILiW PAN and KN PZITB, Krynica, 2009 [in Polish].

57. J.A. ŻURAŃSKI, Wind actions on building structures according to the new standard PN-EN 1991-1-4: 2008, Inżynieria i Budownictwo, nr 7, Warszawa, 360-367, 2010 [in Polish].

58. J.A. Żurański, M. GaczeK, Climatic actions on building structures according to Eurocode 1. Commentaries and examples of calculations, Instytut Techniki Budowlanej, Designing with Eurocodes, Warszawa, 2011 [in Polish].

59. J.A. Żurański, M. GaczeK, S. Fiszer, Instruction for mitigation of strong wind damage to buildings, Instytut Techniki Budowlanej, Warszawa, 2013 (in preparation) [in Polish]. 